\title{
A Numerical Program for Steady-State Flow of Magma- Gas Mixtures Through Vertical Eruptive Conduits
}

USGS Open-File Report 00-209

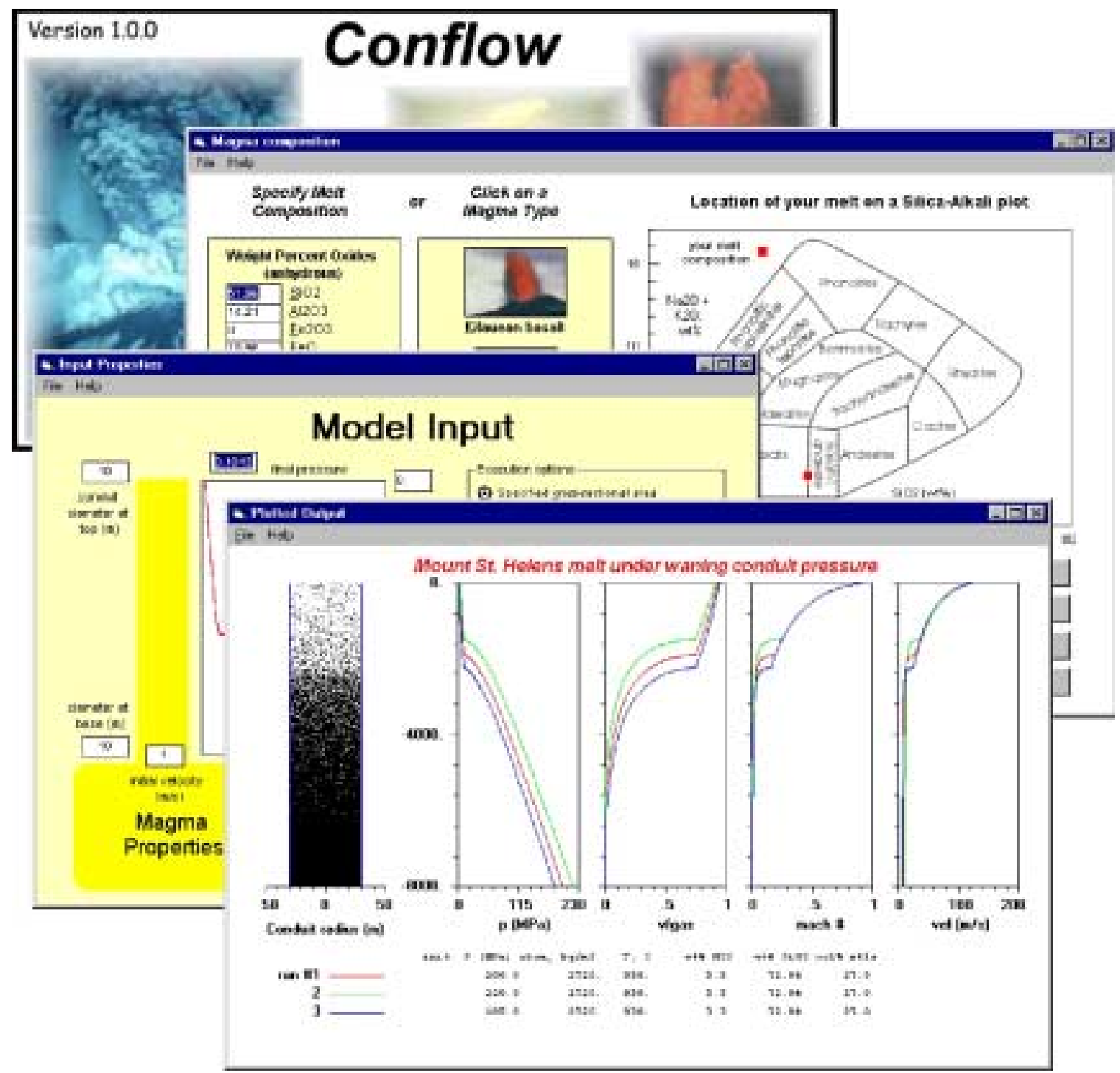



U.S. Department of the Interior

U.S. Geological Survey

\section{A Numerical Program for Steady-State Flow of Magma-Gas Mixtures through Vertical Eruptive Conduits}

By L.G. Mastin and M.S. Ghiorso

Open-File Report 00-209 


\section{U.S. DEPARTMENT OF THE INTERIOR BRUCE BABBIT, Secretary}

\section{U.S. GEOLOGICAL SURVEY}

Charles G. Groat, Director

Any use of trade, product, or firm names in this publication is for descriptive purposes only and does not imply endorsement by the U.S. Government

Additional information can be obtained from

U.S. Geological Survey

Cascades Volcano Observatory 5400 MacArthur Blvd.

Vancouver, Washington 98661

http://vulcan.wr.usgs.gov/Projects/Mastin
Copies of this report can be purchased from:

U.S. Geological Survey

Branch of Distribution

Federal Center, Box 25286

Denver, CO 80225

e-mail: infoservices@usgs.gov 


\section{CONTENTS}

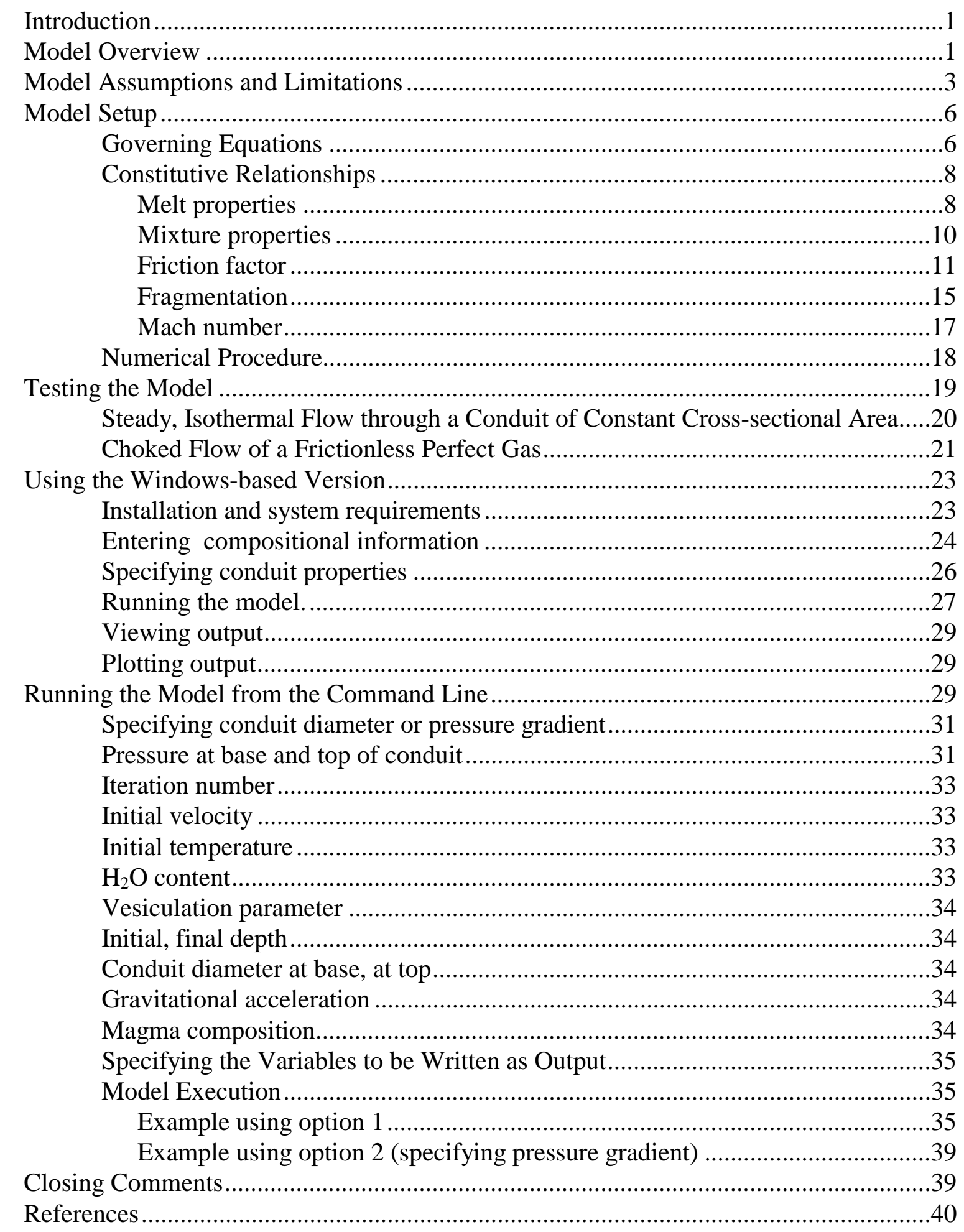


Appendix A: Calculating Melt Thermodynamics .............................................................45

Specific heat, density, and coefficient of thermal expansion of the melt .........45

Thermodynamic properties of the melt .........................................................46

Molar enthalpy of each component ...........................................................47

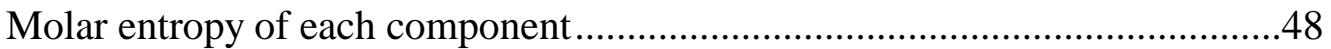

Molar Gibbs free energy of each component .............................................49

Partial Molar Properties...................................................................................50

Appendix B: Calculating the Capillary Number...............................................................51

Appendix C: Modifying the Source Code to use Papale's Fragmentation Criterion ..........52

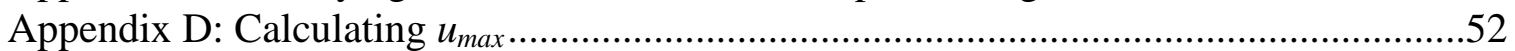

\section{FIGURES}

1. Illustration of the input variables required by the program Conflow..................2

2. Terminal-fall velocity of tephra particles in $\mathrm{H}_{2} \mathrm{O}$ gas at $900^{\circ} \mathrm{C}$.......................

Water solubility versus pressure for albite, rhyolite, and basalt .........................

4. Variation in viscosity with dissolved-water content for rhyolite .......................11

5. Pressure profile in a rhyolitic conduit under various conditions........................22

6. Conduit flow under different fragmentation conditions ...................................26

7. Comparison of properties calculated by Conflow with those calculated

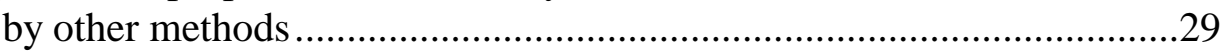

8. Comparison of Conflow results with analytical solution for incompressible flow ............................................................................20

9. Comparison of Conflow results with analytical solution for nozzle

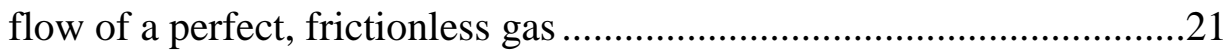

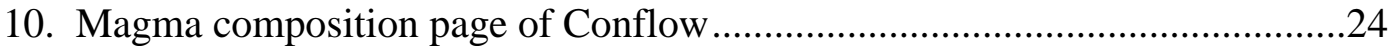

11. Windows for thermodynamic properties, water solubility, and viscosity

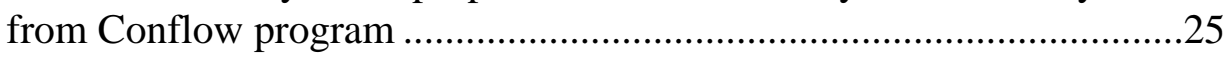

12. Window for conduit properties from Conflow …………………...................26

13. DOS window that opens when the conduit model is launched........................28

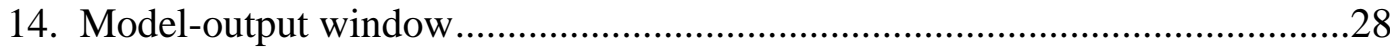

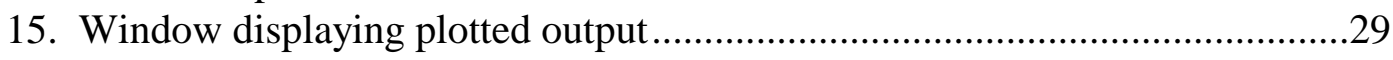

16. Conduit-flow profile for Pinatubo magma under three input pressures............38

\section{TABLES}

1. Compositions of melts used in sample runs.......................................................

A1. Names and formulas of end-member components used in melt ......................45 


\begin{tabular}{|c|c|c|c|c|c|}
\hline Var & Definition & Units & Var & Definition & Units \\
\hline$A$ & cross-sectional area & $\mathrm{m}^{2}$ & $R$ & Universal Gas Constant & $\mathrm{J} /($ mole $\mathrm{K})$ \\
\hline $\boldsymbol{A}$ & empirical constant used in Eq. (19) & -- & $R$ & conduit radius & $\mathrm{m}$ \\
\hline$B$ & empirical constant used in Eq. (19) & -- & $r$ & distance from center of conduit & $\mathrm{m}$ \\
\hline$C$ & sound speed & $\mathrm{m} / \mathrm{s}$ & $r$ & bubble or particle radius & $\mathrm{m}$ \\
\hline$c_{p}$ & specific heat at constant pressure & $\mathrm{J} /(\mathrm{kg} \mathrm{K})$ & $R e$ & Reynolds number & -- \\
\hline$c_{v}$ & specific heat a constant volume & $\mathrm{J} /(\mathrm{kg} \mathrm{K})$ & $s$ & specific entropy & $\mathrm{J} /(\mathrm{kg} \mathrm{K})$ \\
\hline $\bar{c}_{p}$ & molar heat at constant pressure & $\mathrm{J} /($ mole $\mathrm{K})$ & $\bar{s}$ & molar entropy & $\mathrm{J} /($ mole $\mathrm{K})$ \\
\hline $\mathrm{Ca}$ & capillary number & -- & $T$ & temperature & ${ }^{\circ} \mathrm{C}$ or $\mathrm{K}$ \\
\hline$C_{D}$ & Coefficient of drag & -- & $u$ & velocity & $\mathrm{m} / \mathrm{s}$ \\
\hline$D$ & conduit diameter & $\mathrm{m}$ & $u_{\max }$ & maximum theoretical velocity & $\mathrm{m} / \mathrm{s}$ \\
\hline$f$ & friction factor & -- & $\boldsymbol{v}$ & volume fraction & -- \\
\hline$G_{\infty}$ & elastic modulus at infinite frequency & $\mathrm{Pa}$ & $\hat{v}$ & volume fraction in melt & -- \\
\hline$g$ & gravitational acceleration & $\mathrm{m} / \mathrm{s}^{2}$ & $v$ & specific volume & $\mathrm{m}^{3} / \mathrm{kg}$ \\
\hline$g$ & specific Gibbs Free Energy & $\mathrm{J} / \mathrm{kg}$ & $\bar{v}$ & molar volume & $\mathrm{m}^{3} /$ mole \\
\hline $\bar{g}$ & molar Gibbs Free Energy & $\mathrm{J} / \mathrm{mole}$ & $z$ & distance above base of conduit & $\mathrm{m}$ \\
\hline$\underline{h}$ & specific enthalpy & $\mathrm{J} / \mathrm{kg}$ & $\beta$ & empirical Henry's-Law constant & -- \\
\hline $\bar{h}$ & molar enthalpy & $\mathrm{J} / \mathrm{mole}$ & $\dot{\varepsilon}$ & shear strain rate & $\mathrm{s}^{-1}$ \\
\hline$K$ & bulk modulus & $\mathrm{Pa}$ & $\gamma$ & ratio of specific heats & -- \\
\hline$k$ & Proportionality constant in Eq. (26) & -- & $\lambda$ & surface tension of melt & $\mathrm{Pa} / \mathrm{m}$ \\
\hline$m$ & mass fraction in erupting mixture & -- & $\eta$ & viscosity of erupting mixture & $\mathrm{Pa} \mathrm{s}$ \\
\hline$M$ & mass & $\mathrm{kg}$ & $\mu$ & specific chemical potential & $\mathrm{J} / \mathrm{kg}$ \\
\hline$\dot{M}$ & mass flux & $\mathrm{kg} / \mathrm{s}$ & $\bar{\mu}$ & molar chemical potential & $\mathrm{J} / \mathrm{mole}$ \\
\hline$\hat{m}$ & mass fraction in melt & -- & $\Phi$ & integral of $v d p$ for water in melt & $\mathrm{J} / \mathrm{mole}$ \\
\hline$N$ & constant used in viscosity eq. 23 & -- & $\rho$ & mixture density & $\mathrm{kg} / \mathrm{m}^{3}$ \\
\hline$N$ & bubble-number density & $\mathrm{m}^{-3}$ & $\sigma$ & empirical Henry's-Law constant & $\mathrm{Pa}^{-\beta}$ \\
\hline$n$ & moles & -- & $\tau$ & structural melt relaxation time & s \\
\hline$p$ & pressure & $\mathrm{Pa}$ or $\mathrm{MPa}$ & & & \\
\hline$p_{o}$ & reservoir pressure for ideal gas & $\mathrm{Pa}$ or $\mathrm{MPa}$ & & & \\
\hline
\end{tabular}

\begin{tabular}{clcl}
\hline Subscript & \multicolumn{1}{c}{ Definition } & Subscript & \multicolumn{1}{c}{ Definition } \\
\hline app & apparent property of melt & ideal & $\begin{array}{l}\text { value assuming ideal pseudogas behavior } \\
\text { reservoir value (for ideal }\end{array}$ \\
pr & country rock & $o$ & $\begin{array}{l}\text { pseudogases) } \\
\text { or value at base of conduit }\end{array}$ \\
$e$ & value after equilibrating to 1 atm pressure & & component at reference $p$ and $T$ \\
$f$ & final value in conduit & $r$ & constant entropy conditions \\
fusion & fusion (e.g., Sfusion $_{\text {e enthalpy of fusion) }}$ & $s$ & property of solid \\
$g$ & gas & $w$ & water \\
$i$ & component $i$ & $x$ & crystal phase(s) \\
$m$ & melt & 1 & value at base of conduit
\end{tabular}

\begin{tabular}{cl}
\hline Superscript & \multicolumn{1}{c}{ Definition } \\
\hline liq & component in liquid \\
$o$ & end-member component in liquid
\end{tabular}




\title{
A Numerical Program for Steady-State Flow of Magma-Gas Mixtures through Vertical Eruptive Conduits
}

\author{
By L.G. Mastin and M.S. Ghiorso
}

\section{Introduction}

In many volcanic studies, estimates must be made of the changes that magma and its associated gases experience when traveling through an eruptive conduit to the surface. Exsolution of magmatic gas, acceleration, changes in pressure and temperature, depth of fragmentation, and final exit velocities affect such features as lava fountain heights, the ability of a volcanic column to convect or collapse, and the degree to which water can enter the conduit during eruptive activity. Most of these quantities cannot be easily estimated without some sort of numerical model.

This report presents a model that calculates flow properties (pressure, vesicularity, and some 35 other parameters) as a function of vertical position within a volcanic conduit during a steady-state eruption. The model idealizes the magma-gas mixture as a single homogeneous fluid and calculates gas exsolution under the assumption of equilibrium conditions. These are the same assumptions on which classic conduit models (e.g., Wilson and Head, 1981) have been based. They are most appropriate when applied to eruptions of rapidly ascending magma (basaltic lava-fountain eruptions, and Plinian or sub-Plinian eruptions of intermediate or silicic magmas) that contains abundant nucleation sites (microlites, for example) for bubble growth.

The numerical parts of the program were written in Fortran 90 and can be compiled on any platform (DOS, Unix, Macintosh etc.) that has a Fortran 90 compiler. The source code to this model (with the exception of certain subroutines taken from Press et al., 1992) is posted on the USGS Cascades Volcano Observatory web site http://vulcan.wr.usgs.gov. The executable version that is distributed for the Microsoft Windows ${ }^{\circledR}$ operating system includes a graphical user interface with utilities that calculate physical properties of melts, gases, and melt-gas mixtures. Scientists or educators who are not directly interested in conduit modeling may still find these utilities useful. The program is free of charge.

\section{Model Overview}

In any vigorous magmatic eruption, magma is driven up a conduit from some deep location to the Earth's surface. As it rises, gases come out of solution, forming bubbles that expand to the point where they break the magma into tiny fragments. Those fragments become entrained in a jet of accelerating gas that vents violently into the atmosphere. At any given depth in the conduit, the pressure, velocity, volume fraction of entrained gas, temperature, and other characteristics depend on two sets of factors: (1)

\footnotetext{
${ }^{1}$ Department of Geological Sciences, University of Washington, Seattle WA 98195-1310 USA
} 
the initial pressure, temperature, and composition of the mixture; and (2) the length and geometry of the conduit.

The model presented in this paper calculates flow properties using one of two methods. Under option 1 (Fig. 1, left side), the user specifies the conduit diameter at the base and top; the program then solves for the pressure and other flow properties as a function of depth. Under option 2 (Fig. 1, right side), the user specifies the initial conduit diameter and a pressure gradient in the conduit; the program then calculates the conduit geometry required to produce that pressure gradient.

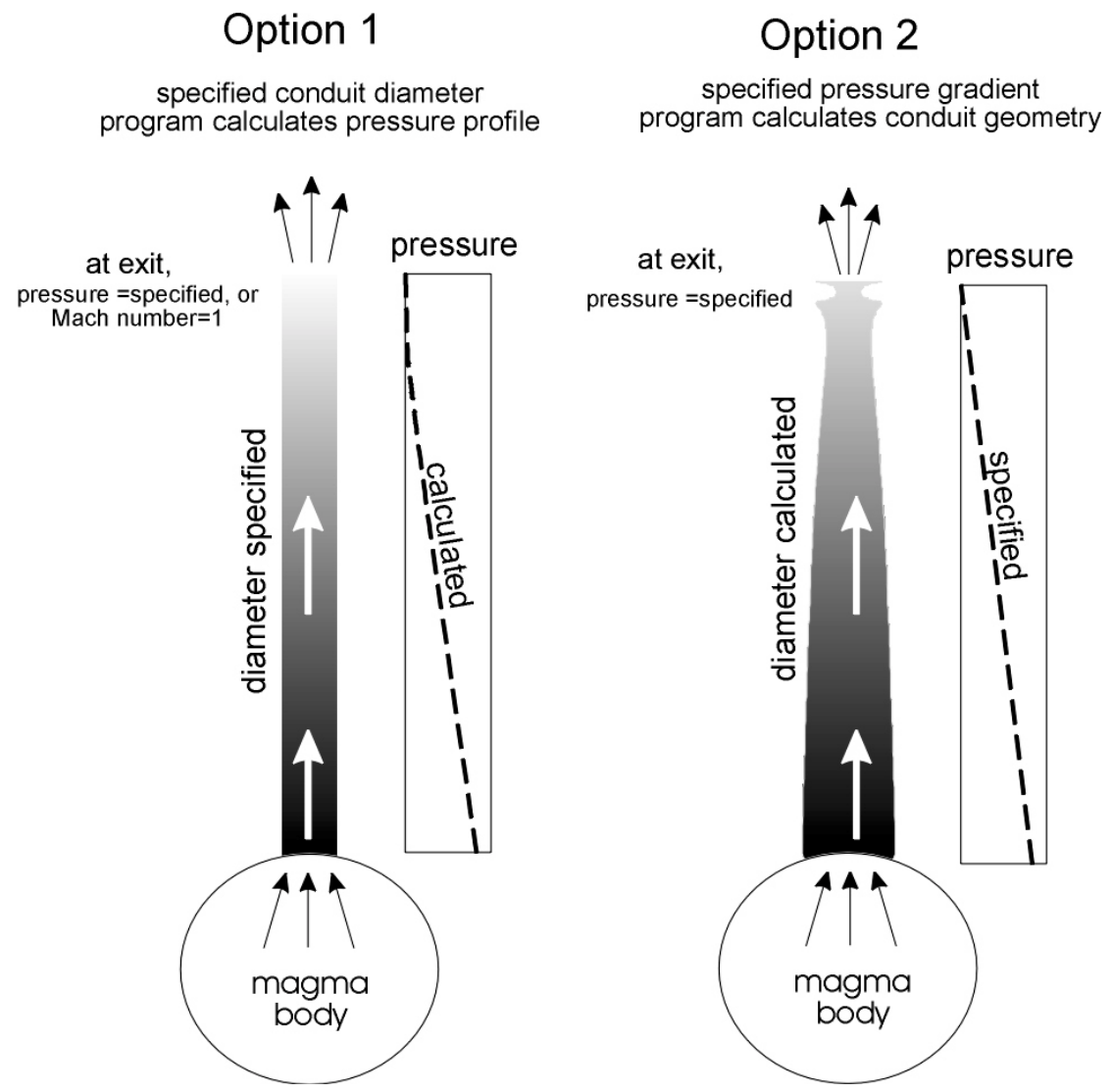

Figure 1: Illustration of the input variables required by the program Conflow, and the two options available for calculating flow properties as a function of depth.

In option 1, the erupting mixture must satisfy one of two conditions: (1) if the exit velocity is less than its sonic velocity, the exit pressure must equal a specified final pressure (usually $1 \mathrm{~atm}$ at the exit). Alternatively, (2) the exit velocity must equal the sonic velocity. The latter boundary condition results from the fact that, in a conduit of constant cross-sectional area, the velocity of the mixture can never exceed its sonic velocity. This is a basic tenet of compressible fluid dynamics and is explained in a number of texts (e.g., Saad, 1985). Thus if the input pressure at the base of the conduit is raised above a certain threshold value, the erupting mixture will not be able to equilibrate to 1 atm pressure by the time it reaches the surface. The exit conditions will vary according to the input pressure, as shown below: 
Input pressure

$\leq$ pressure of static magma column ( $\rho g z)$

slightly greater than $\rho g z$

much greater than $\rho g z$
Exit velocity

0 (no eruption)

subsonic

sonic
Exit pressure

$1 \mathrm{~atm}$

$1 \mathrm{~atm}$

$>1 \mathrm{~atm}$

The sonic velocity of mixtures of ash and gas generally range from a few tens to a few hundreds of meters per second.

In order to match the exit conditions with the required boundary conditions, the program makes successive runs, adjusting the input velocity after each one, until one of the two exit boundary conditions is satisfied. In option 2, successive runs are not necessary-- an output pressure of 1 atm can be achieved during a single iteration by calculating the geometry that gives the specified pressure gradient. The sonic boundary condition does not apply because the variable conduit geometry allows the erupting mixture to accelerate to supersonic velocities.

\section{Model Assumptions and Limitations}

In constructing the model, we make several simplifying assumptions. Foremost among these is that the flow of magma and exsolved gases is homogeneous. That is, there is no relative movement between the gas and liquid as they ascend the conduit. This assumption allows the mixture to be treated as a single fluid whose density, viscosity, and other properties are bulk values for the mixture. The homogeneous-flow assumption is used by other modelers of volcanic eruptions, both mafic and silicic (e.g., Wilson et al., 1980; Wilson and Head, 1981; Head and Wilson, 1987; Buresti and Casarosa, 1989; Giberti and Wilson, 1990), although its validity has been challenged for certain types of eruptions or eruptive flow regimes (Vergniolle and Jaupart, 1986; Dobran, 1992).

Whether the gas separates from the magma and rises at a different velocity depends largely on the size of individual bubbles or pyroclasts, and on the opportunity for bubbles to coalesce or aggregate into larger ones that rise or fall more rapidly through the fluid in which they're suspended. The velocity $(u)$ at which bubbles rise through a melt, and pyroclasts fall through a gas, can be calculated from the following formula (Bird et al., 1960, p. 182):

$$
u=\sqrt{\frac{8 r\left(\rho_{m}-\rho_{g}\right)}{3 \rho_{g} C_{D}}}
$$

where $r$ is the bubble or particle radius; $\rho_{m}$ and $\rho_{g}$ are melt and gas densities, respectively, and $C_{D}$ is the drag coefficient of the bubble or particle, which is a function of its shape and of the Reynolds number $(R e)$. For purposes of this calculation, $R e \equiv 2 \rho u r / \eta$, where $\rho$ is magma density (for bubbles) or gas density (for particles); $u$ is the velocity of the bubble or particle relative to the surrounding fluid; and $\eta$ is the viscosity of the surrounding melt (for bubbles) or gas (for particles)).

For spheres at $R e<\sim 1$, the drag coefficient can be shown analytically to be 24/Re (Bird et al., 1960, p. 192). For $1<R e<\sim 1000$, experimental studies have shown that 
$C_{D} \approx 18.5 / R e^{5 / 3}$; for $1000<R e<\sim 200,000, C_{D} \approx 0.44$ for spheres (Bird et al., 1960, p. 192), and 0.44-1.2 for non-spherical objects (Hoerner, 1965; Walker et al., 1971). The relative movement of gas and melt has different degrees of importance below and above the depth at which magma fragments into particles that are entrained in gas. These differences are as follows:

Below the fragmentation depth. Assuming the bubbles to be spherical and using typical values of the variables in Eq. (1) for silicic melts, the ascent velocity of the bubbles within the melt is so small $\left(<10^{-8} \mathrm{~m} / \mathrm{s}\right)$ relative to ascent velocities of the melt-gas mixtures $\left(10^{-2}-10^{2} \mathrm{~m} / \mathrm{s}\right)$ that the homogeneous flow assumption is reasonable. In basaltic lava-fountain eruptions, the small bubble-diameters (0.1-1 mm Mangan et al., 1993; Mangan and Cashman, 1996) also produce bubble-ascent rates $\left(\sim 10^{-7}-10^{-5} \mathrm{~m} / \mathrm{s}\right)$ within the melt that are much slower than the ascent rate of the overall melt $\left(10^{-2}-10^{2} \mathrm{~m} / \mathrm{s}\right)$. Thus the assumption of homogeneous flow should apply to these eruptions as well. The model tends to break down for basaltic eruptions where bubble diameters exceed about $1 \mathrm{~cm}$ and ascent rates are less than about $10^{-2} \mathrm{~m} / \mathrm{s}$ (Parfitt and Wilson, 1995; Vergniolle and Jaupart, 1986). Under these conditions the behavior of basaltic eruptions usually changes from fountaining to Strombolian or effusive activity.

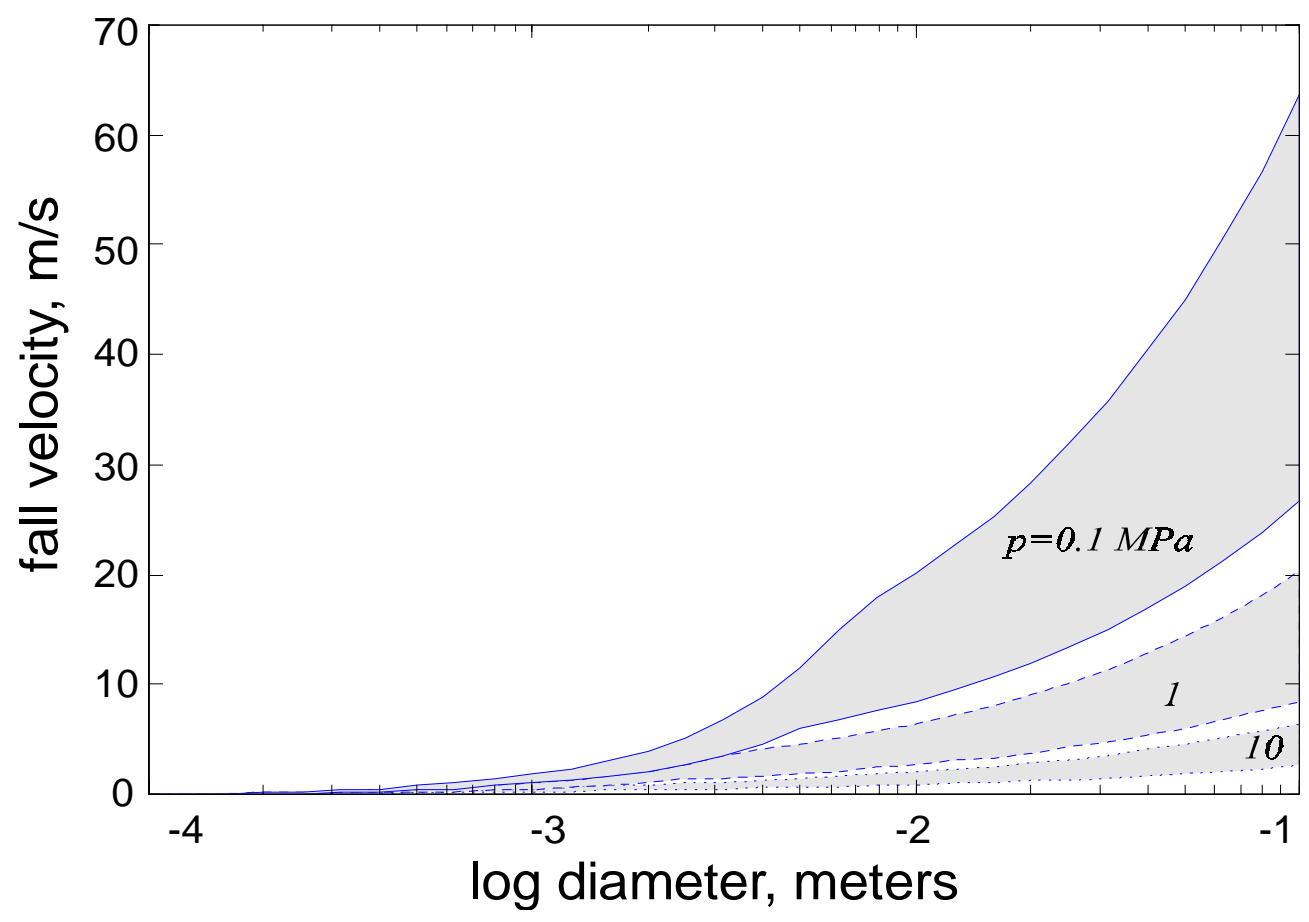

Figure 2: Terminal-fall velocity of melt particles in $\mathrm{H}_{2} \mathrm{O}$ gas at $T=900^{\circ} \mathrm{C}$, as a function of the particle diameter. The three gray regions represent terminal-fall velocities through gases of three different densities: (1) $0.185 \mathrm{~kg} / \mathrm{m}^{3}$--representative of $\mathrm{H}_{2} \mathrm{O}$ gas at $900 \mathrm{C}$ and $1 \mathrm{~atm}$ pressure; (2) $1.849 \mathrm{~kg} / \mathrm{m}^{3}$, representing the same gas at $p=1 \mathrm{MPa}$; and (3) 18.673 , representing $\mathrm{H}_{2} \mathrm{O}$ gas at $p=10 \mathrm{MPa}$. The upper boundary of each gray region represents the terminal-fall velocity of spherical clasts of density $2500 \mathrm{~kg} / \mathrm{m}^{3}$. The lower boundary represents the terminal-fall velocity of clasts of density $1000 \mathrm{~kg} / \mathrm{m}^{3}$, having a $C_{D}$ of 1.0 at $R e>130$. 
Above the fragmentation depth. Figure 2 illustrates the terminal velocity of clasts falling through gas having the density of $\mathrm{H}_{2} \mathrm{O}$ gas at $10 \mathrm{MPa}, 1 \mathrm{MPa}$, and $0.1 \mathrm{MPa}$ (and $900^{\circ} \mathrm{C}$ ), as a function of sphere diameter. For melt particles $0.1 \mathrm{~mm}$ to $1 \mathrm{~mm}$ in diameter, their fall velocity is on the order of a meter per second or less, which is small if the gasascent velocity is tens of meters per second or more. For melt particles larger than several millimeters, fall velocities could be meters per second or greater; which could be a significant fraction of the ascent velocity of the mixture.

The effect of separated two-phase flow was investigated by Dobran (1992), who found that exit velocities were $15-25 \%$ higher under separated flow than homogeneous flow, and that exit pressures were one fourth to one half that of homogeneous models. The different flow properties propagate down the conduit to produce somewhat different profiles of velocity and pressure with depth (Fig. 3 of Dobran, 1992). Because they consider the flow of two phases explicitly, separated-flow models are more accurate than the homogeneous flow models-provided that they contain appropriate assumptions regarding particle-size distribution and particle shape. The differences between homogeneous and inhomogeneous models are generally smaller than differences due to uncertainties in viscosity and certain other variables (described later). One goal of future work will be to incorporate separated flow into this model.

Other assumptions are:

1. Gas exsolution maintains equilibrium with pressure in the conduit up at least to the point of fragmentation. Beyond that point, the user has the option of shutting off additional gas exsolution (under the assumption that gas exsolution cannot keep pace with rates of decompression). This assumption has been made in other models of conduit flow (Wilson et al., 1980; Wilson and Head, 1981; Giberti and Wilson, 1990; Dobran, 1992; Papale and Dobran, 1993; Papale et al., 1998; Mastin, 1995b, 1997), though kinetic calculations and some experimental work (Mangan and Sisson, 1999) suggest that bubble growth may be limited by kinetics. To date, only the model by Proussevitch and Sahagian (1996) attempts to consider the kinetics of gas exsolution explicitly.

2. At any given depth, flow properties can be averaged across the entire crosssectional area of the conduit. This assumption simplifies the problem to a onedimensional one.

3. The conduit is vertical.

4. Flow is steady state. This assumption is appropriate for eruptions that are sustained for many minutes to hours-i.e. basaltic lava fountains and Plinian or subPlinian eruptions.

5. No heat is transferred across the conduit walls during the eruption. For sustained eruptions through conduits on the order of $10 \mathrm{~m}$ diameter and $1 \mathrm{~km}$ long, the heat flux through the conduit walls is generally two to five orders of magnitude less than that driven convectively up the conduit, suggesting that this assumption is appropriate (Woods, 1995).

6. The gas, melt, and crystals maintain thermal equilibrium during flow. Because thermal equilibration times for particles of the size typically produced during volcanic eruptions are on the order of fractions of a second to a few seconds (Wilson and Head, 1980), this assumption is reasonable. 
7. The gas phase consists only of $\mathrm{H}_{2} \mathrm{O}$ gas. With the exception of certain alkalic ultramafic magmas, water is the dominant volatile species of erupting melts. The solubility of water in melts is also much better understood than that of other gas species, or of multicomponent volatile compositions.

8. There is no migration of gas through the conduit walls. This assumption limits applicability of the model to cases where gas generation is sufficiently rapid that bubbles cannot migrate to the margin of the conduit before they are released at the surface. The assumption is appropriate for lava-fountain eruptions, where vesicle residence times are less than a minute, and for silicic high-flux rate eruptions, where the combination of melt viscosity and rapid magma ascent limit the opportunity for gas to separate from the flow. In slowly fed eruptions, gas escape may reduce the vesicularity of the erupted magma, resulting in the effusion of lava flows rather than pyroclastic debris (Eichelberger et al., 1986; Jaupart and Allègre, 1991; Woods and Koyaguchi, 1995).

\section{Model Setup}

The following section presents the constitutive and governing equations on which the computations are based.

\section{Governing Equations}

Using the assumptions described earlier, we can write equations for conservation of mass,

$$
\frac{d(\rho u A)}{d z}=0
$$

momentum,

$$
\rho u \frac{d u}{d z}=-\rho g-\rho u^{2} \frac{f}{R}-\frac{d p}{d z}
$$

and energy

$$
\mathrm{d} h+u \mathrm{~d} u+g d z=0
$$

of the erupting mixture. The variables $\rho, u$, and $p$ are the density, velocity, and pressure of the mixture in the conduit, respectively; $A$ is the conduit's cross-sectional area; $g$ is gravitational acceleration; $f$ is a friction factor whose value controls frictional pressure loss in the vent (Bird et al., 1960); $\boldsymbol{R}$ is the radius of the conduit; $z$ is vertical position (upwards being positive); and $h$ is specific enthalpy of the magma-gas mixture.

Equation 2 states simply that an expansion of the erupting mixture must be accompanied by acceleration, or by an increase in cross-sectional area within the vent in order to avoid movement of material into a space already occupied. The equation is derived from the postulate that the mass flux, $\dot{M}=\rho u A$, is constant at all points in the

\footnotetext{
${ }^{2}$ The friction factor defined by Bird et al. (1960), used here, differs by a factor of four from that defined by Schlichting (1968, p. 86) and used by Wilson et al. (1980). Therefore the second term on the right-hand side of Eq. (2) also differs from the corresponding term in Eq. (1) of Wilson et al. (1980).
} 
conduit. Equation 3 indicates that acceleration within the vent may result from (1) gravitational forces (first term on the right-hand side), (2) frictional forces associated with flow (middle term), and (3) the pressure gradient (right term). Equation 4 states that changes in enthalpy of the magma-gas mixture (the first term) are balanced by changes in kinetic energy (the second term) and elevation potential energy (the third term).

By rearranging Eq. (2) as $\mathrm{d} u=-u(d \rho / \rho+d A / A)$, substituting it into the term on the left side of Eq. (3), and rearranging, the following equation is obtained:

$$
-\frac{d p}{d z}=\rho g+\rho u^{2} \frac{f}{\boldsymbol{R}}-\frac{\rho u^{2}}{A} \frac{d A}{d z}-u^{2} \frac{d \rho}{d z}
$$

This equation can be made more tractable by assuming that the right-hand term, $d \rho / d z$, is approximately equal to the product $(\partial \rho / \partial p)_{\mathrm{s}}(d p / d z)$. The term $(\partial \rho / \partial p)_{\mathrm{s}}$ is the partial derivative of density with respect to pressure under constant entropy for the gas-magma mixture. For homogeneous mixtures of gas dispersed in liquid (or vice versa), it can easily be calculated. Just as importantly, this quantity is the squared reciprocal of sound speed of the mixture, $C$ (Liepmann and Roshko, 1957, p. 50). Equation (5) can therefore be rewritten as

$$
-\frac{d p}{d z}\left(1-\frac{u^{2}}{C^{2}}\right)=\rho g+\rho u^{2} \frac{f}{\boldsymbol{R}}-\rho \frac{u^{2}}{A} \frac{d A}{d z}
$$

or,

$$
-\frac{d p}{d z}=\frac{\rho g+\rho u^{2} \frac{f}{\boldsymbol{R}}-\frac{\rho u^{2}}{A} \frac{d A}{d z}}{1-M^{2}}
$$

where $M$ is the Mach number of the mixture, i.e. its velocity divided by its sonic velocity.

Equation (7) is used to calculate the pressure and pressure gradient in the conduit. It reveals some fundamental properties of the pressure at various states of flow. Under static conditions, $u=0$ and $M=0$, and the pressure gradient is simply $-d p / d z=\rho g$, or the gradient due to the static weight of the magma column. If magma is flowing, but at a velocity that is small relative to its sonic velocity, $M=\sim 0$ and the pressure gradient is a function of the weight of the magma column, frictional pressure losses (i.e. the first and second terms in the numerator on the right side of Eq. (7)), and changes in conduit geometry (the third term). As $M$ approaches 1, the numerator on the right hand side of Eq. (7) must approach zero in order to avoid a singular solution. Setting $A=\pi \boldsymbol{R}^{2}$, the numerator on the right side of Eq. (7) must satisfy the following equality in order to be equal to zero:

$$
\rho g+\frac{f \rho u^{2}}{\boldsymbol{R}}=\frac{\rho u^{2}}{\pi \boldsymbol{R}^{2}} \frac{2 \pi \boldsymbol{R} d \boldsymbol{R}}{d z}
$$


Rearranging leads to:

$$
\frac{d \boldsymbol{R}}{d z}=\frac{1}{2}\left(\frac{\boldsymbol{R} g}{u^{2}}+f\right)
$$

Because the two terms on the right hand side of Eq. (9) are always positive, the vent must be slightly widening in the upward direction in order for the sonic velocity to be reached (Wilson and Head, 1981). In a constant-area duct, the velocity can never reach $M=1$ regardless of the driving pressure at the base of the conduit (though from computational experience it can come extremely close). An increase in pressure at the base of the conduit will result in an increase in pressure at the conduit exit and an increase in mass flux (due to greater density of the mixture at the exit). It will not, however, result in an increase in the exit Mach number beyond $M=1$. The escaping magma-gas mixture will equilibrate with atmospheric pressure abruptly above the exit, through a series of shock waves (Liepmann and Roshko, 1957; Kieffer, 1989).

In a gradually flaring conduit, If $M<1$ at the point where $d \boldsymbol{R} / d z$ satisfies Eq. (9), and the conduit continues to diverge, the mixture will decelerate with increasing $z$ and the pressure drop will be relatively modest. If, on the other hand, $M=1$ is achieved in this critical section and the conduit continues to diverge, then the fluid will accelerate to supersonic velocity and the pressure will drop significantly with increasing $z$. At this stage, depending on the conduit geometry, the pressure can drop below $p=1 \mathrm{~atm}$ prior to reaching the conduit exit. If this is the case, a stationary shock wave will develop within the diverging section of the conduit, through which the velocity of the erupting mixture will drop abruptly to a subsonic value and pressure will rise to a value that allows the mixture to reach $1 \mathrm{~atm}$ at the conduit exit (Saad, 1985, p. 158).

In a vent containing a constant pressure gradient, Eq. (7) is rearranged to isolate the variable $d A / d z$ as follows:

$$
\frac{d A}{d z}=\frac{A}{\rho u^{2}}\left[\frac{d p}{d z}\left(1-M^{2}\right)+\rho g+\frac{f \rho u^{2}}{\boldsymbol{R}}\right]
$$

This equation is used to calculate changes in cross-sectional area for model runs in which the pressure gradient is specified.

\section{Constitutive Relationships}

The following constitutive relationships are used to evaluate the terms on the righthand side of equations 7 and 10 .

M elt properties

Gas solubility. The mass fraction of dissolved gas $\left(\hat{m}_{w}\right)$ in the melt is calculated as follows: (1) the chemical potential of water in the melt $\left(\bar{\mu}_{w}\right)$ is calculated using methods of Ghiorso and Sack (1995; the "MELTS" method) for a given pressure, temperature, and melt chemistry (including assumed mass fraction dissolved water). (2) The chemical 
potential of the $\mathrm{H}_{2} \mathrm{O}$ gas phase $\left(\bar{\mu}_{g}\right)$ is calculated using thermodynamic relations of Haar et al. (1984). (3) The mass fraction dissolved water $\left(\hat{m}_{w}\right)$ in the melt is adjusted until its chemical potential equals that of the gas phase. The method of Ghiorso and Sack (1995) is summarized in Appendix A. Gas solubilities predicted using this method are reasonable approximations to experimental data (Fig. 3) and can be made without a priori knowledge of solubility for a given magma type.

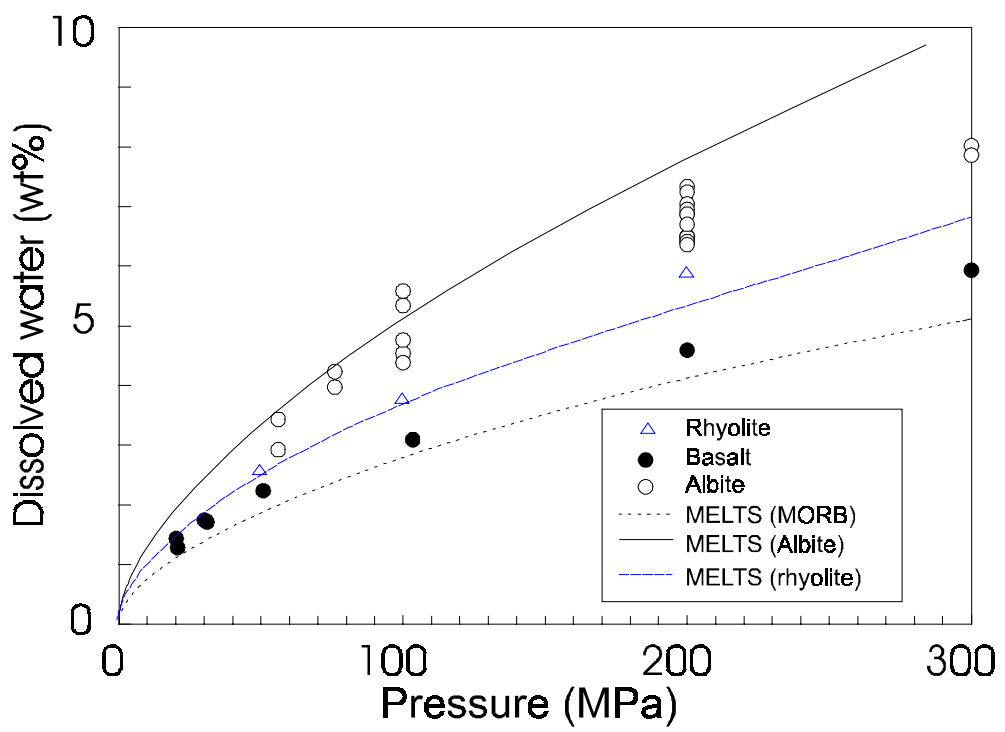

Figure 3: Water solubility (wt\%) versus pressure (MPa) for albite, rhyolite, and mid-ocean ridge basalt (MORB), calculated by MELTS (lines), and measured in selected experiments (symbols). Experimental data for albite taken from Hamilton and Oxtoby (1986); for basalt from Hamilton et al. (1964) and Dixon et al. (1995); and for rhyolite from Holtz et al., (1995, "HPG8" composition). Melt compositions used in the MELTS calculations to generate these lines are given in Table 1.

Table 1. Compositions of melts used for sample runs in this document. Oxide compositions are weight percent of an anhydrous melt. Basalt is a MORB composition taken from Table 2 of Dixon et al., (1995). Pinatubo melt composition taken from Luhr \& Melson (1997). Rhyolite composition represents a haplogranitic melt (HPG8) characterized for its solubility (Holtz et al., 1995) and rheologic properties (e.g., Dingwell et al.,1996; Hess and Dingwell, 1996).

\begin{tabular}{ccccc}
\hline property & basalt & $\begin{array}{c}\text { Mt. St. } \\
\text { Helens }\end{array}$ & Pinatubo & rhyolite \\
\hline temperature $(\mathrm{C})$ & 1200. & 930. & 780. & 750. \\
$\mathrm{SiO}_{2}{ }^{*}$ & 50.80 & 74.18 & 77.53 & 76.69 \\
$\mathrm{Al}_{2} \mathrm{O}_{3}$ & 13.70 & 14.83 & 12.81 & 12.91 \\
$\mathrm{Fe}_{2} \mathrm{O}_{3}$ & 0.00 & 0.00 & 0.00 & 0.61 \\
$\mathrm{FeO}$ & 12.40 & 2.10 & 0.80 & 0.55 \\
$\mathrm{MgO}$ & 6.67 & 0.51 & 0.23 & 0.04 \\
$\mathrm{CaO}$ & 11.50 & 2.39 & 1.30 & 0.29 \\
$\mathrm{TiO}_{2}$ & 1.84 & 0.37 & 0.14 & 0.10 \\
$\mathrm{Na}_{2} \mathrm{O}$ & 0.68 & 5.24 & 4.16 & 4.20 \\
$\mathrm{~K}_{2} \mathrm{O}$ & 0.15 & 0.37 & 2.98 & 4.61 \\
\hline
\end{tabular}

Conflow uses the MELTS procedure to calculate solubility through a range of pressure at the beginning of the model run. It then uses a least-squares routine (Press et al., 1992, p. 659) fits the results to the equation below:

$$
\hat{m}_{w}=\sigma p^{\beta}
$$


where $\hat{m}_{w}$ is the mass fraction dissolved water in the melt (distinguished from $m_{w}$, the mass fraction water in the melt+gas+crystal mixture); and $\sigma$ and $\beta$ are constants whose values are determined by the best-fit procedure. Equation (11) is used to compute $\hat{m}_{w}$ except in cases where the total water in the system is not sufficient to saturate the magma.

2) Mass fraction crystals. The volume fraction crystals in melt $\left(\hat{v}_{x}\right)$ is given as input to the model. The mass fraction crystals in the melt $\left(\hat{m}_{x}\right.$, distinguished from the mass fraction crystals in the mixture, $m_{x}$ ) is calculated from the formula:

$$
\hat{m}_{x}=\frac{\rho_{x} \hat{v}_{x}}{\rho_{x} \hat{v}_{x}+\rho_{m}\left(1-\hat{v}_{x}\right)}
$$

where the crystal density is given as input to the program, and melt density is calculated using method of Ghiorso and Sack (1995; see Appendix A) after computing the dissolved water content of the melt.

\section{Mixture properties}

Mass fractions gas, crystals, and melt. The mass fraction gas in the total system is equal to the total water in the system minus that dissolved in the melt ${ }^{6}$. It is calculated from the following equation:

$$
\begin{aligned}
m_{g} & =m_{w}-m_{m} \hat{m}_{w} \\
& =m_{w}-\left(1-m_{x}-m_{g}\right) \hat{m}_{w}
\end{aligned}
$$

where $m_{x}$ and $m_{m}$ are the mass fractions of crystals and melt in the mixture, respectively. By substituting $\hat{m}_{x}\left(1-m_{g}\right)=m_{x}$ and rearranging, we get:

$$
m_{g}=\frac{m_{w}-\left(1-\hat{m}_{x}\right) \hat{m}_{w}}{1-\left(1-\hat{m}_{x}\right) \hat{m}_{w}}
$$

Mass fractions of the crystals and melt are then calculated as follows:

$$
\begin{aligned}
& m_{x}=\left(1-m_{g}\right) \hat{m}_{x} \\
& m_{m}=1-m_{g}-m_{x}
\end{aligned}
$$

Volume fractions. Volume fractions ( $V$ ) of the three phases are calculated as follows:

\footnotetext{
${ }^{3}$ In this model, the water incorporated into minerals is ignored.
} 


$$
v_{i}=\frac{\frac{m_{i}}{\rho_{i}}}{\frac{m_{g}}{\rho_{g}}+\frac{m_{m}}{\rho_{m}}+\frac{m_{x}}{\rho_{x}}}
$$

where the subscript $i$ refers to one of the three phases; gas $(g)$, melt $(m)$, or crystals $(x)$. The density of the gas is calculated using relations of Haar et al. (1984) at the current absolute temperature $(T)$ and $p$. Densities of the other phases are calculated as explained for Eq. (12).

Density. The bulk density of the mixture, $\rho$, is:

$$
\rho=\frac{1}{\left(m_{g} \boldsymbol{V}_{g}+m_{m} \boldsymbol{V}_{m}+m_{x} \boldsymbol{V}_{x}\right)}
$$

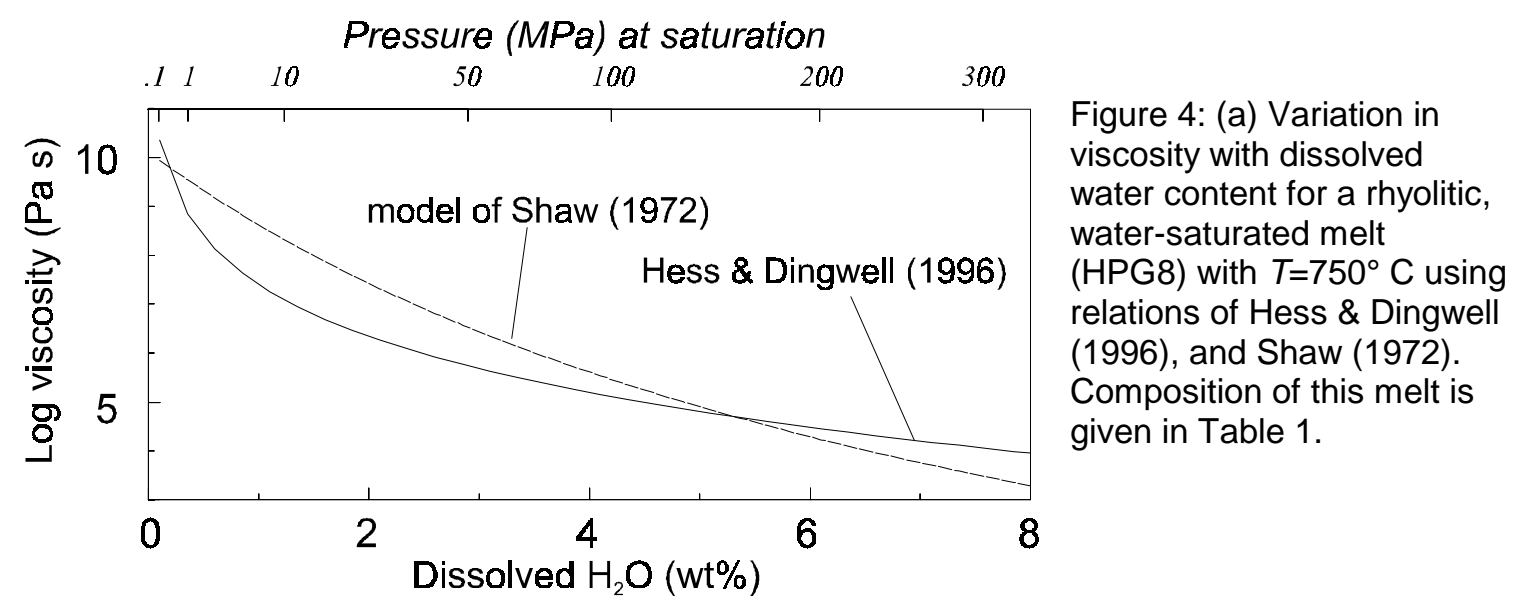

Friction factor

The frictional resistance of single-phase fluids flowing in cylindrical conduits is well known from experimental data (e.g., Bird et al., 1960, p. 186). Frictional resistance is generally expressed as a friction factor, $f$, defined as the force resisting flow through a unit length of a conduit, normalized to the surface area of the conduit in that path length and to the kinetic energy per unit volume of the flowing mixture (Bird et al., 1960, p. 181). Following previous investigators (Wilson et al., 1980; Giberti and Wilson, 1990; Dobran, 1992), we calculate $f$ from the following equation:

$$
f=\frac{16}{R e}+f_{o}=\frac{16 \eta}{\rho u D}+f_{o}
$$

where $D$ is the conduit diameter, $\eta$ is the viscosity of the mixture, and $R e$ is the Reynolds number, defined as $\rho u D / \eta$. The variable $f_{\mathrm{o}}$ is an empirically derived factor related to the roughness of the conduit walls. In Conflow it is assumed to be 0.0025 . 


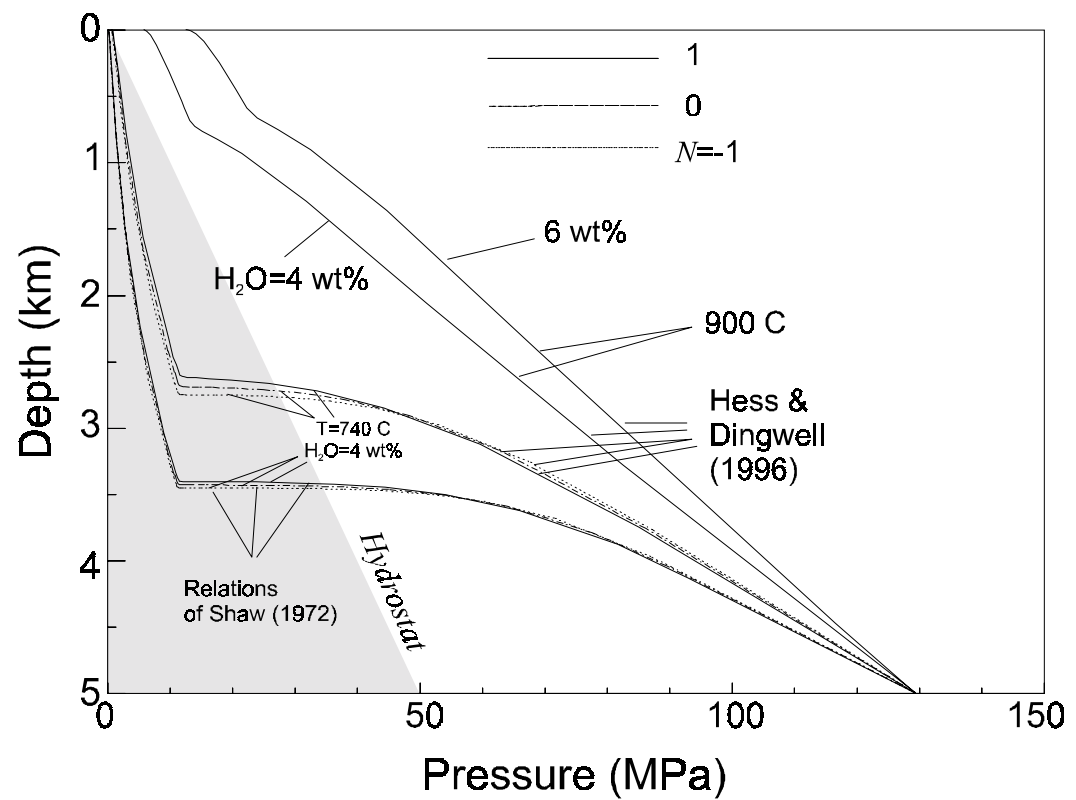

Figure 5: Pressure profile in a 100-m-diameter conduit for high-silica rhyolite (composition given in Table 3) with choked flow at the exit, $p=130 \mathrm{MPa}$ at $5 \mathrm{~km}$ depth. The lowermost three curves use viscosity relations of Shaw (1972) and input temperature of $740 \mathrm{C}$; all other lines use viscosity relations of Hess and Dingwell (1996) and input temperatures as indicated. The significance of the variable $N$ is explained on p. 18-19.

For laminar-flow conditions $(R e<\sim 2000)$, which characterize nearly the entire conduit below the fragmentation depth, the left-hand term on the right side dominates Eq. (18). The velocity $u$ is determined with knowledge of $\rho$ and $A$ using the continuity equation (Eq. (2)), and $D$ is calculated or specified. At Reynolds numbers typical for turbulent flow (generally, the conduit section above the fragmentation depth), the friction factor $f$ is determined primarily by the right-hand term, $f_{\mathrm{o}}$, in Eq. (18). Experimental values of $f_{\mathrm{o}}$ range from about 0.001 to 0.02 ; values of around 0.0025 are commonly used to model flow in rough-walled eruptive conduits (Wilson et al., 1980; Giberti and Wilson, 1990), and we use that value here. Variations in $f_{\mathrm{o}}$ between 0.002 and 0.02 have an insignificant effect on conduit pressures for basaltic and silicic magmas.

Viscosity of the melt. The viscosity $(\eta)$ of the mixture varies greatly during ascent due to vesiculation, fragmentation, heating or cooling, and the exsolution of dissolved water. The method of Shaw (1972) remains the only one that allows viscosity to be calculated for any given melt composition and temperature. Conflow uses this method for all melts containing less than $70 \% \mathrm{SiO}_{2}$ by weight (anhydrous). The method of Shaw (1972) assumes that the viscosity of the melt $\left(\eta_{m}\right)$ is Arrhenian, i.e. that it obeys the relation:

$$
\log \left(\eta_{m}\right)=\boldsymbol{A}+\boldsymbol{B} / \mathbf{T}
$$

where $\boldsymbol{A}$ and $\boldsymbol{B}$ are empirical constants which are functions of melt composition, and $T$ is absolute temperature. The method for calculating $\boldsymbol{A}$ and $\boldsymbol{B}$ is described in Shaw (1972). For melts containing more than $70 \%$ silica, Conflow uses a non-Arrhenian viscosity relation published by Hess and Dingwell (1996) .

\footnotetext{
${ }^{4}$ In Hess and Dingwell's original equation, water content was expressed in weight percent. I have converted the equation so that water content is expressed in mass fraction of the melt.
} 


$$
\log \left(\eta_{m}\right)=.2911+0.833 \ln \left(\hat{m}_{w}\right)+\frac{-1304-2368 \ln \left(\hat{m}_{w}\right)}{T-\left(344+32.25 \ln \left(\hat{m}_{w}\right)\right)}
$$

where viscosity is in Pascal seconds and temperature $(T)$ is in Kelvin. This relation gives substantially lower viscosities than Shaw (1972) at dissolved water contents of 1.5-2.5 $\mathrm{wt} \%$, and higher viscosities for water contents $<0.5 \mathrm{wt} \%$ (Fig. 4). For silicic melts, these viscosity relations produce much different pressure profiles (Fig. 5).

Effect of crystals on viscosity. The presence of crystals in the melt generally increases resistance to flow. Studies in the engineering literature (e.g., Einstein, 1906, 1911; Hess, 1920; Eilers, 1943; Roscoe, 1952; Gay et al., 1969; Jeffrey and Acrivos, 1976) and in the Earth Sciences (e.g., Shaw, 1965, 1969; Kerr and Lister, 1991; Pinkerton and Stevenson, 1992; LeJeune and Richet, 1995) suggest that the rheology of a crystalline melt depends on the volume fraction crystals and on their shape. In general, melts remain Newtonian as long as crystals make up less than a few tens of percent of the mixture (by volume; Pinkerton and Stevenson, 1992; Lejeune and Richet, 1995). At higher volume fraction the mixture develops a yield strength (Kerr and Lister, 1991; Pinkerton and Stevenson, 1992). The Einstein-Roscoe equation is generally used to calculate the viscosity $\left(\eta_{m+x}\right)$ of a crystal-melt mixture (e.g., Marsh, 1981; Pinkerton and Stevenson, 1992; Lejeune and Richet, 1995):

$$
\eta_{m+x}=\eta_{m}\left(1-\frac{v_{x}}{v_{\max }}\right)^{-2.5}
$$

where $V_{\max }$ is the volume-fraction crystals at which maximum packing is achieved. For roughly equant crystals packed irregularly, Marsh (1981) suggests that $v_{\max } \approx 0.6$. That value is used in Conflow.

Neither Conflow nor any other current volcanic-conduit model handles the nonNewtonian rheologies of melts at high crystal fractions. If you enter a crystallinity above $30 \%$ while using Conflow, you will receive the following warning:

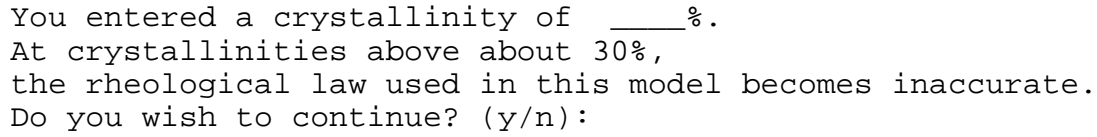

If you enter more than 59 volume percent crystals, you will receive the following error message:

$$
\begin{aligned}
& \text { You entered a crystallinity of } \quad \text { \% } \\
& \text { This program cannot handle crystallinities above 59\%. Program stopped. }
\end{aligned}
$$

Effect of bubbles on viscosity. Although numerous investigators have measured the rheology of foams and emulsions (see, for example, issues of Journal of Rheology or Journal of Colloid and Interface Science), few studies have explicitly addressed the rheology of bubbly melts; and those few studies have reached rather variable conclusions. Experiments on $\mathrm{GeO}_{2}$ containing from 0.8 to $5.5 \mathrm{vol} \%$ air bubbles (Stein and Spera, 1992) found substantial increases in viscosity with bubble-volume fraction; but 
oscillatory-strain experiments on extremely high-viscosity rhyolite (Bagdassarov and Dingwell, 1992) found decreases in viscosity with increasing bubble volume fraction.

Manga et al. (1998) appear to offer an explanation of these discrepancies by explaining that the bulk viscosity is a function of the capillary number:

$$
C a \equiv \frac{\eta_{m+x} \dot{\varepsilon} r}{\lambda}
$$

where $\dot{\varepsilon}$ is the shear strain rate of the suspension, $r$ is the average undeformed bubble radius, and $\lambda$ is the surface tension of the liquid. For $C a<<1$, bubbly melts tend to be more viscous than the liquid alone, while for $C a>\sim 1$ they tend to be less viscous. In general, bubbly mafic melts have lower capillary numbers than silicic melts; hence mafic melts should tend to increase in viscosity with vesicularity; silicic ones to decrease.

For low capillary numbers, the amount by which viscosity changes with volume fraction gas is not well defined. Taylor (1932) suggests that viscosity of emulsions containing sparse fluid droplets varies as $\eta=\eta_{m+x}\left(1+V_{g}\right)$ (for $\eta_{g}<<\eta_{m+x}$ ). Dobran (1992) uses the relation $\eta=\eta_{m+x} /\left(1-v_{g}\right)$ ( for $\left.\eta_{g}<<\eta_{m}\right)$. The increase in viscosity with $v_{\mathrm{g}}$ given by Dobran's equation is more modest than that for hard spherical inclusions (Roscoe, 1952), but greater than that for liquid droplets (Taylor, 1932), or for bubbles at $C a=0.3$ calculated numerically for silicate melts (Manga et al., 1998). The viscosity predicted by relations of Dobran (1992) is also significantly less than that used by Jaupart and Allègre (1991) based on experimental measurements of Sibree (1933) for bubbly liquids; and is less than relations derived by Stein and Spera (1992) for bubbly $\mathrm{GeO}_{2}$ melts. As pointed out by Manga et al. (1998), the experiments of Sibree (1933) may not be applicable to silicate melts because an organic colloid produces adsorption layers on the bubble walls of his liquids. Similarly, the results of Stein and Spera (1992), which produce viscosities greater than that expected for hard spheres, may have been affected by quenching or crystallization along bubble walls (Manga et al., 1998). In the absence of more definitive data, the relation of Dobran appears to be a reasonable approximation of $\eta$ for $C a<<1$.

For $C a>>1$, the bulk viscosity approaches a theoretical limit of $\eta=\eta_{m+x}\left(1-V_{g}\right)$ (Manga et al., 1998). Based on this relationship and that of Dobran (1992), one could postulate a bulk viscosity given by:

$$
\eta=\eta_{m+x}\left(1-v_{g}\right)^{N}
$$

where $N$ is an adjustable constant that varies from $\sim 1$ (for $C a<<1$ ) to $\sim-1$ (for $C a>>1$ ). For basaltic melts, pressure and velocity profiles are not especially sensitive to the particular viscosity-vesicularity relationship (Mastin, 1995b, Fig. 7). For silicic melts, the nature of the viscosity-vesicularity relationship could dramatically affect flow properties, as described later.

Conflow calculates bulk viscosity using Eq. (23) and an estimated value of $N$ as follows:

$$
N=\frac{2}{\pi} \tan ^{-1}(5 \cdot \log (C a))
$$


where the Capillary number is calculated as described in Appendix B. This relation has been chosen simply because it changes gradually from asymptotic values of -1 at $C a<<1$ to 1 at $C a>>1$. Additional research may lead to an improved understanding of the rheology of bubbly liquids.

Viscosity above the fragmentation depth. At high vesicularity, the bubbly suspension breaks up into a gas entraining particles of melt. For the viscosity of the fragmented mixture, Conflow uses the following relation (Dobran, 1992):

$$
\eta=\eta_{g}\left[\frac{1-v_{g}}{0.62}\right]^{-1.56}
$$

\section{Fragmentation}

The point at which the melt breaks up into small fragments entrained by gas is of great importance in controlling dynamics of conduit flow. That point has traditionally been assumed to take place when $v_{g} \cong 0.75$, the gas volume fraction at which spherical bubbles reach a closest-packing structure (Sparks, 1978). Several conduit models (e.g., Wilson and Head, 1980; Wilson et al., 1981; Giberti and Wilson, 1990; Dobran, 1992) use $V_{\mathrm{g}}=0.75$ as a criterion for fragmentation. Conflow uses this criterion as well.

Recent studies have explored more physically based fragmentation mechanisms, including the degree of overpressure in bubbles (Alidibirov, 1994; Alidibirov and Dingwell, 1996) and shock-wave propagation (Barmin and Melnik, 1993). Papale (1999) suggests that fragmentation takes place when the extensional-strain rate $\left(\dot{\varepsilon}_{z z}\right)$ within the conduit exceeds that which can be accommodated by viscous flow. Papale's criterion is expressed mathematically as follows:

$$
\dot{\varepsilon}_{z z}=\frac{d u}{d z}>\frac{k}{\tau}=k \frac{G_{\infty}}{\eta}
$$

where $(\mathrm{d} u / \mathrm{d} z)$ is the vertical velocity gradient, $k$ is an empirical constant, $\tau$ is the magma structural relaxation time, $\eta$ is the viscosity of the mixture, and $G_{\infty}$ is the "elastic" modulus of the bubbly liquid at infinite frequency. Using values of $k=0.01, G_{\infty}=25 \mathrm{GPa}$, and $\eta=\eta_{m+x} /\left(1-V_{g}\right)$, Papale tested this criterion for rhyolitic, dacitic, and basaltic conduit flow. He found that fragmentation took place when the volume fraction gas range from about 0.62 to 0.93 , with higher values for mafic melts and lower values for silicic ones. Using Papale's fragmentation criterion, Mastin (1999) found that the depth of fragmentation and other flow properties in the conduit vary dramatically depending on the exact relation for $\eta$ (i.e. constant versus variable $N$; Fig. 7). Fragmentation depths and flow properties are also highly sensitive to values of $k$ and $G_{\infty}$. 

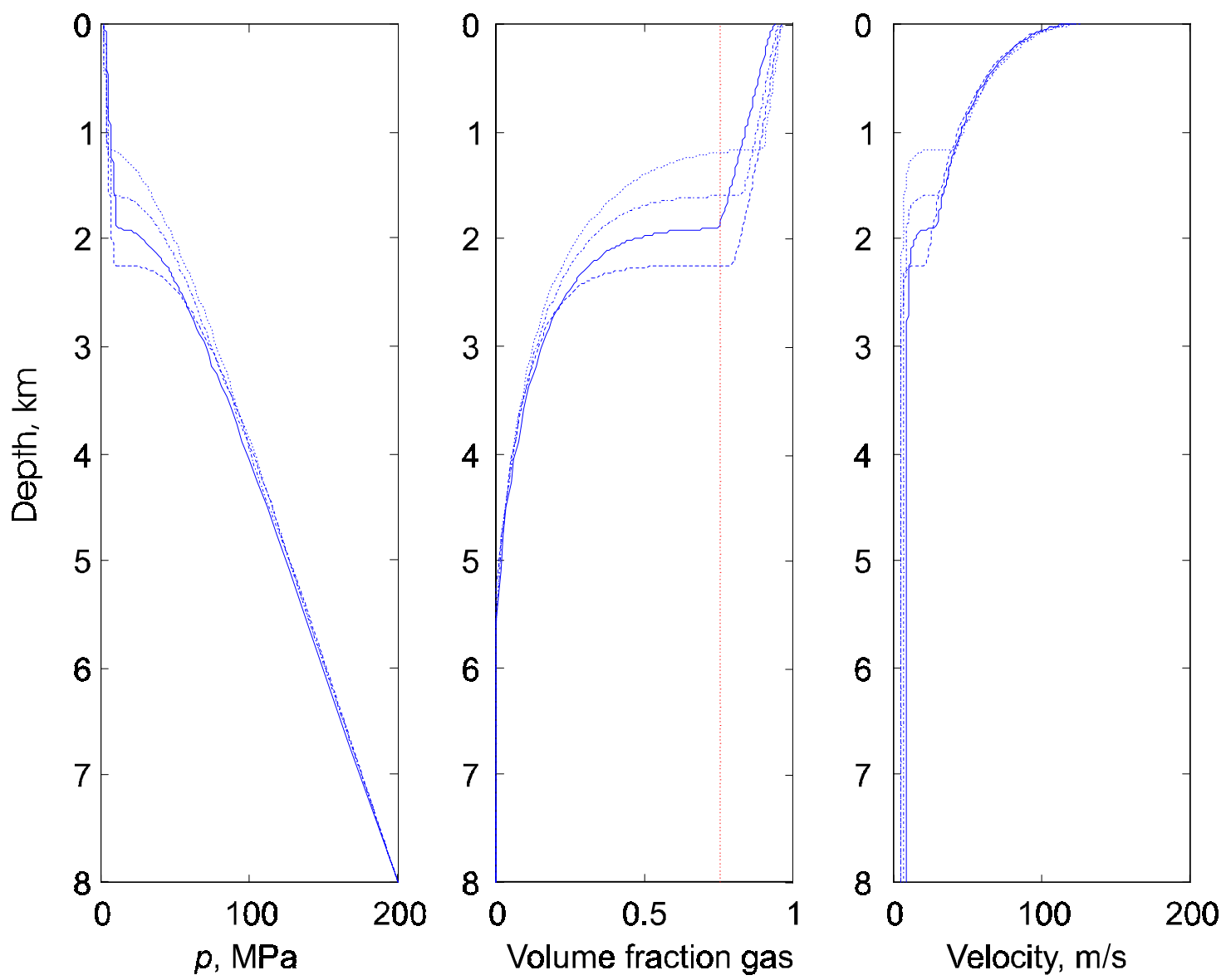

Figure 6: Comparison of results for conduit flow of Mount St. Helens magma using a fragmentation criterion of $v_{g}=0.75$ (solid line) and a strain-rate based fragmentation criterion (the three other lines). The parameters used to generate these profiles are described in the text. The long-dashed line represents flow profiles generated with the values of $k, G_{\infty}$ and $\eta$ used by Papale, including calculation of $\eta_{m}$ using relations of Shaw (1972). The dot-dashed line represents profiles generated using the same relations, but calculating $\eta_{m}$ using relations of Hess and Dingwell (1996). The dotted line uses the same relations as the dot-dashed line, but with a value of $\eta$ (Eq. 23) that depends on capillary number. The initial melt composition, pressure and temperature used in these models are listed in Table 1. Conduit diameter $=60 \mathrm{~m}$.

With some minor modifications of the source code (described in Appendix C), Conflow is capable of using Papale's fragmentation criterion. The Papale fragmentation criterion is not available in the standard executable program because there is still a great deal of uncertainty regarding both the appropriate numerical values (or mathematical relations) for $k, G_{\infty}$, and $\eta$, and their appropriate definitions. For example, the elastic modulus $G_{\infty}$ used to calculate the brittle failure of elongating glass fibers is the elongational (or Youngs) modulus; but in eruptive conduits with rigid conduit walls, the bulk modulus may be more appropriate. For glass, the former ranges from about 25 to 78 $\mathrm{GPa}$, while the latter is about twice that (Bansal and Doremus, 1986). Papale uses a constant value of $G_{\infty}$; but for a bubbly mixture the value of $G_{\infty}$ must decrease dramatically as gas volume fraction increases. 
Similarly, for viscosity, Papale (1999) used the standard Newtonian shear viscosity for $\eta$, though the criterion for brittle failure of glass fibers uses the elongational viscosity, which relates extensional strain rate to tensile stress. Elongational viscosity is generally about three times the shear viscosity (Webb and Dingwell, 1990). For conduits with rigid walls, a third viscosity, termed the volumetric viscosity, may be the most important. The volumetric viscosity relates volumetric changes of the mixture to pressure differential (Thomas et al., 1994; Kaminski and Jaupart, 1997). Its value is not well established.

Conflow users who employ Papale's criterion should do so after devoting some careful thought to the parameters involved and their significance. The high sensitivity of flow properties to such factors as viscosity may reflect a real instability in eruptive dynamics; that is, minor changes in crystal content, temperature, or melt chemistry during an eruption may produce significant changes in eruptive dynamics. Additional study of the criteria that control fragmentation, using this model, would be a fruitful avenue of research.

Mach number

The Mach number of the mixture is its velocity divided by the mixture's (approximate) sonic velocity $(C)$. The latter is defined as

$$
C^{2}=\left(\frac{\partial p}{\partial \rho}\right)_{s}
$$

where the subscript $s$ indicates constant entropy conditions. This equation can also be written in terms analogous to seismic velocity equations, as

$$
C^{2}=\frac{K}{\rho}
$$

where $K$ is the bulk modulus of the mixture under adiabatic (constant-entropy) conditions. For a dispersed mixture of particles in gas, the bulk modulus is:

$$
\frac{1}{K}=\frac{v_{m}}{K_{m}}+\frac{v_{g}}{K_{g}}+\frac{v_{x}}{K_{x}}
$$

where $v_{m}, v_{g}$, and $v_{x}$ represent the volume fraction of the three phases, and $K_{m}, K_{g}$ and $K_{x}$ their bulk moduli. The bulk modulus of the crystals is assumed to be approximately $10^{5}$ MPa. The bulk modulus of unvesiculated magma is calculated using the method of MELTS, given in Appendix A (for the melt, we assume that the isothermal bulk modulus is essentially equal to the isentropic bulk modulus). The bulk modulus of the gas phase can be calculated from ideal gas relations:

$$
K_{g}=\rho_{g}\left(\frac{\partial p}{\partial \rho}\right)_{s}=\rho_{g} \frac{c_{p g}}{c_{v g}}\left(\frac{\partial p}{\partial \rho}\right)_{T}
$$


where the subscripts $s$ and $T$ refer to constant entropy and constant temperature, respectively. All of the terms on the right-hand side can be calculated using the Haar et al. (1984) equation of state for $\mathrm{H}_{2} \mathrm{O}$.

\section{Numerical Procedure}

For the case of specified cross sectional area in the conduit, all terms on the righthand side of Eq. (7) can be determined as long as the pressure and velocity at the base of the conduit are specified. By calculating $d p / d z$ from Eq. (7), a new pressure can be extrapolated to a higher point in the conduit. The continuity equation, Eq. (2), as well as the constitutive relations in equations 11-30 and the appendices, can be used to evaluate density, velocity, friction factor, and Mach number at this new depth. Using these values, a new $d p / d z$ can be evaluated using Eq. (7), and the procedure is repeated to the top of the conduit. For the case of constant pressure gradient, the procedure is the same except that a new gradient in cross-sectional area is evaluated at each depth using Eq. (10), rather than a new pressure gradient using Eq. (7).

The integration is carried out using a Cash-Carp method with automatic quality control that adjusts the vertical step size to concentrate calculations at points where properties are changing most rapidly (Press et al., 1992).

Temperature changes at each depth are calculated using the following equation, which is modified from Eq. (4):

$$
h=h_{1}+\frac{1}{2}\left(u_{1}^{2}-u^{2}\right)+g\left(z_{1}-z\right)
$$

where $u_{1}, \mathrm{z}_{1}$, and $h_{1}$ are the velocity, elevation, and enthalpy at the base of the conduit; and $u, z$, and $h$ are the same variables at the current depth. The initial specific enthalpy $\left(h_{1}\right)$ is calculated for the known pressure, temperature, and composition of the melt using the formula:

$$
h=m_{g} h_{g}+m_{m} h_{m}+m_{x} h_{x}
$$

where $h_{g}, h_{m}$, and $h_{x}$ are the specific enthalpies of the gas, melt, and crystals, respectively. The specific enthalpies of the gas and melt are calculated using methods of Haar et al. (1984) and of Ghiorso and Sack (1995), respectively: the specific enthalpy of the crystals is calculated using the following simplified equation:

$$
h_{x}=c_{x} T+\frac{p}{\rho_{x}}
$$

where the specific heat $\left(c_{x}\right)$ and density $\left(\rho_{x}\right)$ of the crystals (assumed constant) are given as input to the program.

At any depth above the base of the conduit, the elevation and velocity are used in Eq. (31) to calculate a new enthalpy of the erupting mixture. For the known pressure and 
composition at that depth, the program adjusts the temperature of the mixture until its enthalpy, calculated using Eq. (32), equals that predicted by Eq. (31).
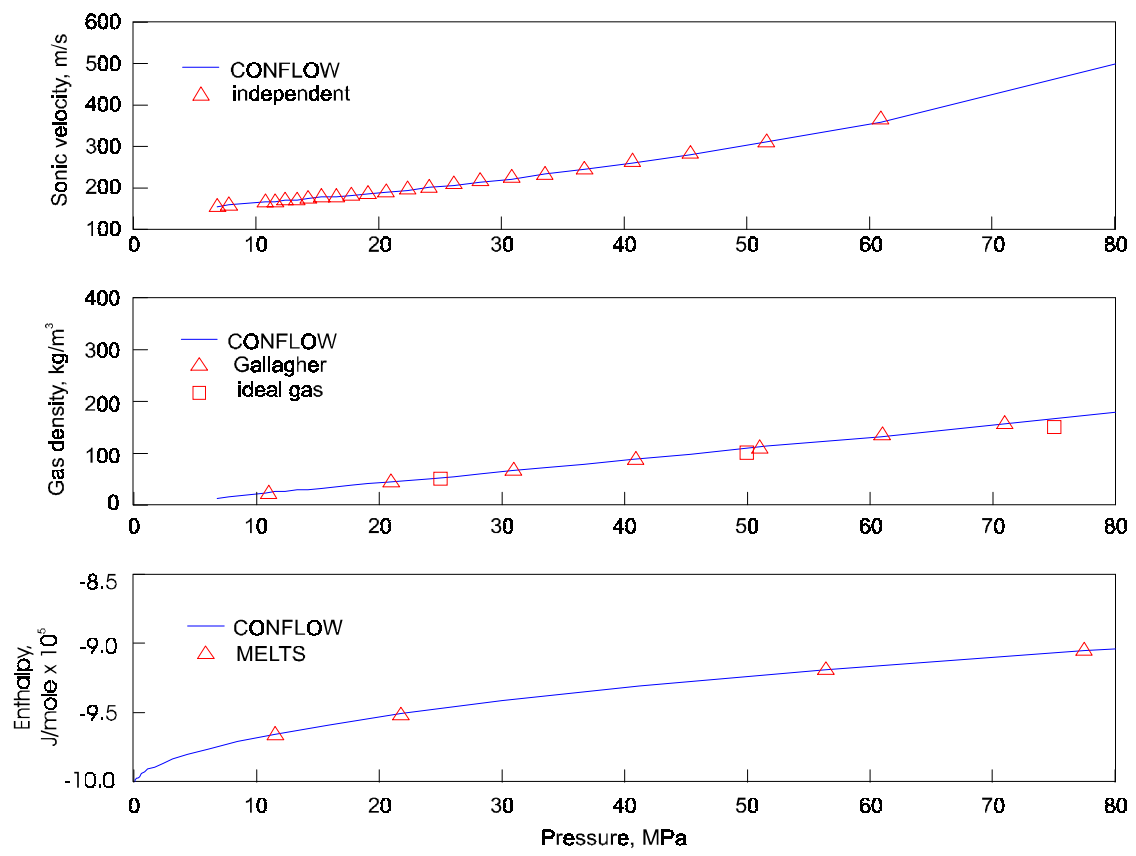

Figure 7: Comparison of certain melt or flow properties calculated by Conflow and calculated by independent methods, for a Mount St. Helens magma at $830 \mathrm{C}$, with $4.6 \mathrm{wt} \%$ total water. These plots indicate the accuracy of Conflow in calculating these properties. In the upper plot, the sonic velocity calculated by Conflow (solid line) is compared with that calculated using the equation:

$$
C=\frac{\boldsymbol{V}_{g}}{\kappa_{g}}+\frac{1-\boldsymbol{V}_{g}}{\kappa_{m+x}}
$$

where the bulk moduli of the gas $\left(K_{g}\right)$ and of the melt+crystals $\left(K_{m+x}\right)$ are calculated by Conflow. In the middle plot, the gas density calculated by Conflow is compared with that calculated using a Fortran program for steam properties provided by J.S. Gallagher of the National Bureau of Standards. For the sake of comparison, we also plot density of an ideal gas (squares) having the molecular weight of water. In the lower plot, the enthalpy of the melt calculated by Conflow is compared with the values for the same $p, T$, and composition calculated by the web-based MELTS calculator (http://weber.u.washington.edu/ ghiorso/).

\section{Testing the Model}

The tests presented in this section illustrate two points: (1) that the model correctly calculates various properties of the erupting mixture as set forth in the constitutive equations; and (2) that the model correctly calculates flow properties for certain endmember situations for which analytical solutions exist.

In addressing point (1), we do not attempt to show exhaustively that every property calculated by Conflow is accurate: however in Fig. 8 we illustrate the accuracy of a few key parameters (sound speed, gas velocity, melt enthalpy) by comparing values calculated by Conflow with independent calculations. The results compare well (as one would expect). 
To address point (2), we calculate conduit flow under two end-member conditions: (1) isothermal flow of a single-phase melt through a conduit of constant cross sectional area; and (2) flow of a perfect gas through a frictionless conduit. The overall results of these end-member tests depend on each of the flow properties: therefore in addressing point (2) above, we are implicitly testing point (1).
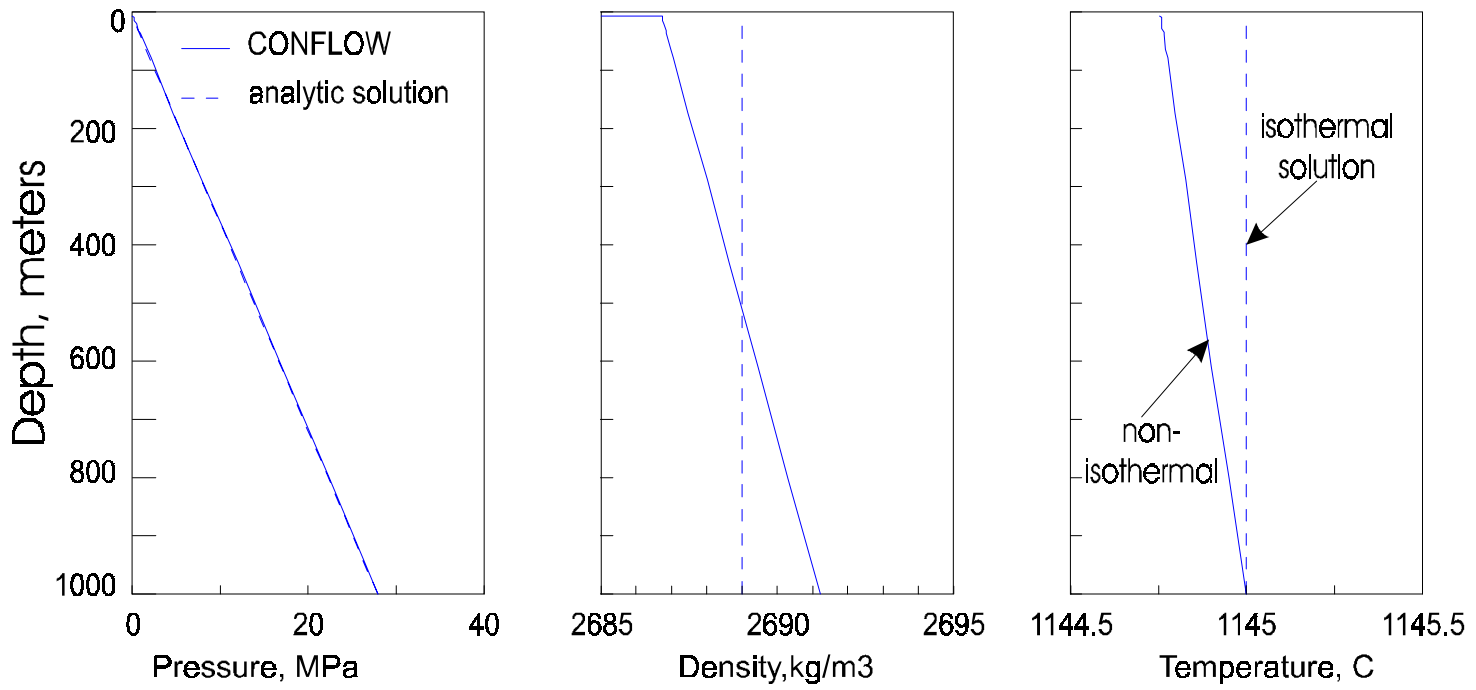

Figure 8: Comparison of flow properties calculated by Conflow (solid lines) and the analytical solution (dashed lines) for isothermal, laminar flow of an incompressible liquid (Kilauean basalt at $1145^{\circ} \mathrm{C}$ ) up a $1-\mathrm{km}$ long vertical conduit, 5 meters in diameter. In the left plot, the results calculated by Conflow are indistinguishable from those of the analytical equation. Conflow considers changes in density (middle plot) and temperature (right-hand plot), which are not considered by the analytical equation; however those changes do not significantly affect the calculations of pressure.

Steady, Isothermal Flow through a Conduit of Constant Cross-sectional Area

The continuity equation (Eq. (2)) for this case reduces to $\rho=$ constant. Equation 5 reduces to

$$
-\frac{d p}{d z}=\rho g+\frac{f \rho u^{2}}{r}
$$

Substituting $f=16 / R e$, and considering that $R e=2 \rho u r / \eta$, the equation can be rewritten as follows:

$$
-\frac{d p}{d z}=\rho g+\frac{8 \rho u}{r^{2}}
$$

This is easily integrated to give:

$$
p_{f}-p_{1}=-\left(\rho g+\frac{8 \rho u}{r^{2}}\right)\left(z_{f}-z_{1}\right)
$$



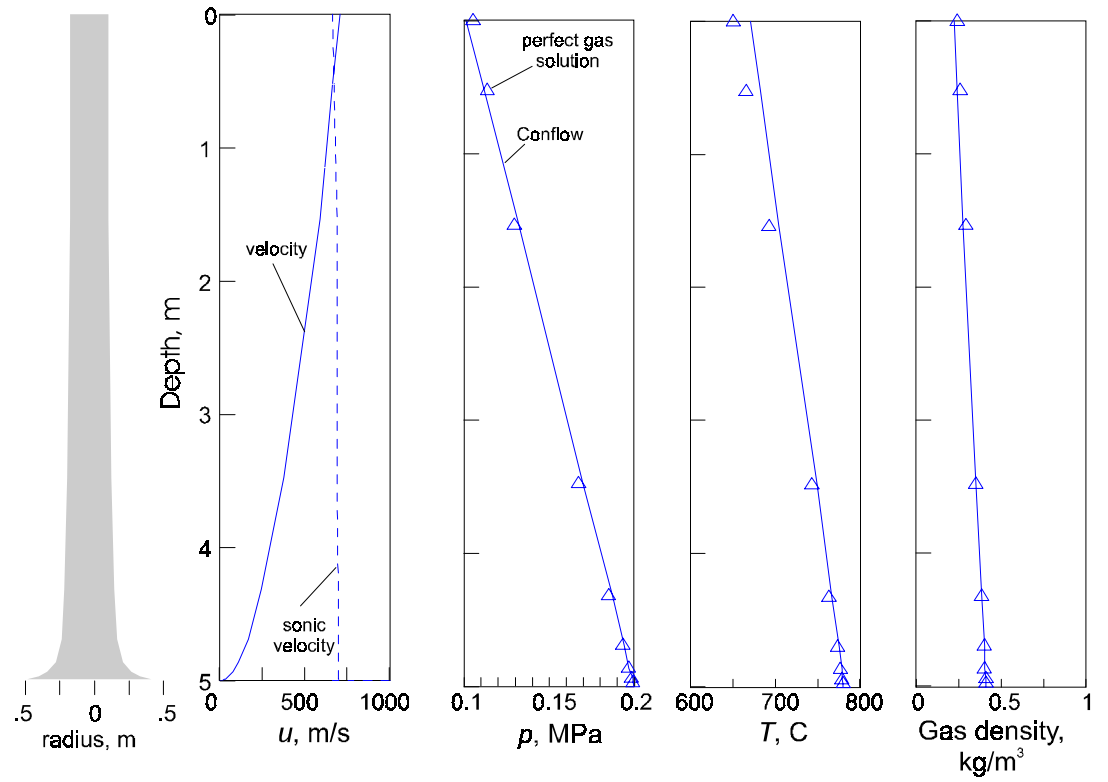

Figure 9: Flow properties in a 5-m long conduit containing pure $\mathrm{H}_{2} \mathrm{O}$ gas, having a diameter at the base of $5 \mathrm{~m}$ and a pressure at the base of $0.2 \mathrm{MPa}$. Solid lines give the flow properties calculated by Conflow: triangles give the flow properties for a perfect gas with $\gamma=1.249$.

and 1 refer to the final and initial values, respectively, of $p$ and $z$. Figure 9 compares the pressure profile (left), melt density (center) and temperature (right) calculated for a Hawaiian basalt using Conflow, and using the analytical solution with a volatile-free magma, initially at $1145^{\circ} \mathrm{C}(21.40 \mathrm{~Pa}$ s viscosity $)$, flowing at $0.001 \mathrm{~m} / \mathrm{s}$ through a $2-\mathrm{cm}-$ diameter conduit (the conduit diameter and velocity had to be adjusted to ensure that flow was laminar). The pressure profile given by Conflow (solid line) matches the analytical solution (dashed line) closely, but not exactly. The discrepancy is due to adiabatic changes in temperature of the magma $\left(\sim 0.25^{\circ}\right.$ cooling after $1000 \mathrm{~m}$ of flow (middle plot), which increases its viscosity by about $0.08 \mathrm{~Pa}$ s (lower plot) and, combined with decompression effects, decreases its density.

\section{Choked Flow of a Frictionless Perfect Gas}

For an ideal gas with specific heats at constant pressure $\left(c_{p}\right)$ and constant volume $\left(c_{v}\right)$ that do not change with temperature, relationships between pressure, temperature, density, Mach number, and other variables for one-dimensional, frictionless flow through nozzles and diffusers are well developed (e.g., Liepmann and Roshko, 1957; Saad, 1985). Those relationships ignore the weight of the fluid (i.e. they leave out the " $\rho g$ " term in Eq. (3) and the $g d z$ term in Eq. (4)). Because those relationships assume ideal gas behavior, they also assume that no new gas is being generated (for example, by exsolution) during flow. Dilute gas/particle mixtures in volcanic eruptions have been occasionally modeled as frictionless, weightless ideal gases (Kieffer, 1981, 1984; Turcotte et al., 1990). Such models assume that the erupting mixtures roughly obey the ideal gas law. The assumption of ideal gas behavior tends to be more valid as the volume fraction (or mass fraction) of gas in the mixture increases.

Using these assumptions, pressure-velocity relationships of adiabatically decompressing ideal pseudogases follow the relationship (Kieffer, 1984):

$$
p v^{\gamma}=\text { constant }
$$


where $\gamma$ is the ratio $c_{p} / c_{v}$ of the gas/particulate mixture. For air, $\gamma=1.4$. For $\mathrm{H}_{2} \mathrm{O}$ gas, $\gamma$ is generally lower (e.g., 1.236 for $\mathrm{H}_{2} \mathrm{O}$ gas at $T=900 \mathrm{C}, p=0.1 \mathrm{MPa}$ ). For gas/particulate mixtures, the parameter $\gamma$ is calculated from the following formula:

$$
\gamma=\frac{c_{p}}{c_{v}}=\frac{m_{g} c_{p, g}+m_{m} c_{p, m}+m_{x} c_{p, x}}{m_{g} c_{v, g}+m_{m} c_{v, m}+m_{x} c_{v, x}}
$$

By combining Eq. (37) with the continuity and momentum equations for an ideal gas, one obtains the following relationships between pressure $\left(p_{\text {ideal }}\right)$, density $\left(\rho_{\text {ideal }}\right)$, temperature $\left(T_{\text {ideal }}\right)$, and Mach number for flow within a nozzle (Saad, 1985, p. 85-88):

$$
\begin{gathered}
\frac{T_{o}}{T_{\text {ideal }}}=1+\frac{\gamma-1}{2} M^{2} \\
\frac{p_{o}}{p_{\text {ideal }}}=\left(1+\frac{\gamma-1}{2} M^{2}\right)^{\frac{\gamma}{\gamma-1}} \\
\frac{\rho_{o}}{\rho_{\text {ideal }}}=\left(1+\frac{\gamma-1}{2} M^{2}\right)^{\frac{1}{\gamma-1}}
\end{gathered}
$$

where $T_{0}, p_{o}$, and $\rho_{o}$ are the temperature (Kelvin), pressure, and density of the mixture in an upstream reservoir where the velocity is negligible. If $T_{o}, p_{o}$, and $\rho_{o}$ are known, and the Mach number at a particular point in the nozzle is known, then the temperature, pressure, and density at those points can be calculated.

An ideal gas/particulate mixture can be approximated in the program Conflow by making the following changes: (1) set the weight percent gas in the system at $100 \%$; (2) set the conduit length to be very short to minimize the effects of gravity and friction in the calculations. Flow through the conduit is then calculated by setting a constant pressure gradient and having the program calculate the cross-sectional profile. The model calculates the Mach number, temperature, density, and pressure at each point. Those properties are plotted (solid lines) as a function of conduit position in Fig. 9 for a 5-m long conduit. At each depth, using the Mach number calculated by Conflow, the ideal gas values of density, pressure, and temperature were calculated using Eqs. (39)-(41). Those values are plotted as triangles.

The ideal gas results are similar but not identical to those give by Conflow. Differences in the results are assumed to be due to (1) the non-ideal properties of $\mathrm{H}_{2} \mathrm{O}$ gas, and (2) friction and gravity effects. 


\section{Using the Windows-based Version}

Installation and system requirements

The program Conflow can be obtained by anonymous ftp by pointing your web browser to the following USGS site:

ftp://elektra.wr.usgs.gov

Once entering this ftp site, go to Pub/lgmastin/conflow. The program Conflow is in the form of a self-extracting Zip file named conflowzip.exe. Source files to the Fortran version of this program are in the subdirectory "source files". The report you are reading is also available in digital form at that site as ofile.pdf (in Portable Document Format). To read the documentation file, you will need Adobe Acrobat Reader ${ }^{\circledR}$, which can be downloaded free of charge at:

http://www.adobe.com/products/acrobat/readstep.html

To install the model, do the following:

1) Copy the file "conflowzip.exe" in the above ftp directory to the hard drive of your Windows-based computer. The zipped file occupies 2.2 megabytes of disk space.

2) Double-click on the file icon. It will then unzip and place the unzipped files in a new directory labeled "conflow." The directory size will be about 3.1 megabytes.

3) Go into the conflow directory, and double-click on the "setup.exe" icon. This will install the program, place the executable files in the directory " $\mathrm{c}: \backslash$ program files\Conflow", and place the icon under the "program" menu of the Start button.

4) To start the program, go to Start >> Programs > Conflow.

If you wish to uninstall the program later, you can do so by going to start >> Settings >> Control Panel, and double-clicking on the icon "Add/Remove Programs". On the "Install/uninstall" tab, choose "Conflow" from the list of programs, then click the "Add/Remove" command button.

Conflow will operate on any Windows ${ }^{\circledR}$-based computer running on an Intel ${ }^{\circledR}$ (or equivalent) 80386 or later processor. Because Conflow is one-dimensional, it does not require large amounts of memory; any recent Windows ${ }^{\circledR}$-based computer should be fast enough to operate it. Informal tests using the program's default input conditions (Kilauean magma, 1-km long conduit) give solution times ranging from about 8 seconds on a Pentium II $500 \mathrm{MHz}$ computer with $64 \mathrm{MB}$ RAM to about 40 seconds on older Pentiums with about $15 \mathrm{Mb}$ RAM. More silicic magmas and longer conduits require longer run times. 


\section{Entering compositional information}

Launching the program will open a window (Fig. 10) which allows you to choose the composition of your melt, its gas content, crystal content, temperature and initial pressure. Here are some tips on using the window.

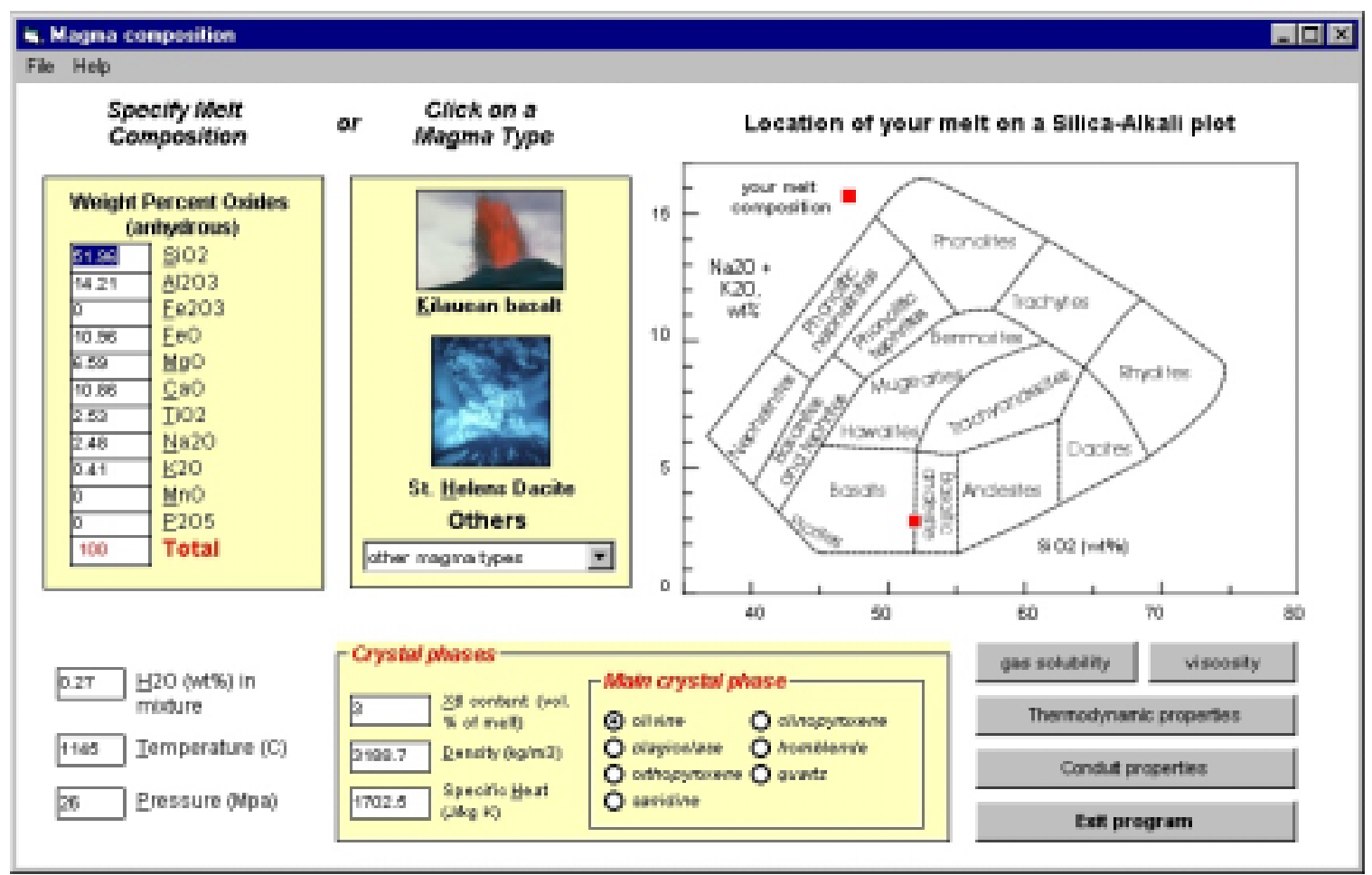

Figure 10: Magma composition page of Conflow

- Entering data. You can enter a composition by typing in the weight percent of the constituent oxides individually (in the left column), or by choosing from one of several pre-defined magma types (right column). The program plots that composition on a silica-alkali diagram (right). The weight percent water, entered in the text box on the lower left, refers to the percent water in the total mixture (melt+crystal+gas), not the dissolved water in the melt alone. The dissolved water content is determined from the total water content and the gas solubility of the melt at the given temperature and pressure.

- Saving and loading data. You can save compositional information to a file by choosing File >> save properties, or load compositional information saved earlier by choosing File >> Load properties." Files of compositional data are in ASCII format and have the suffix ".mpr". 


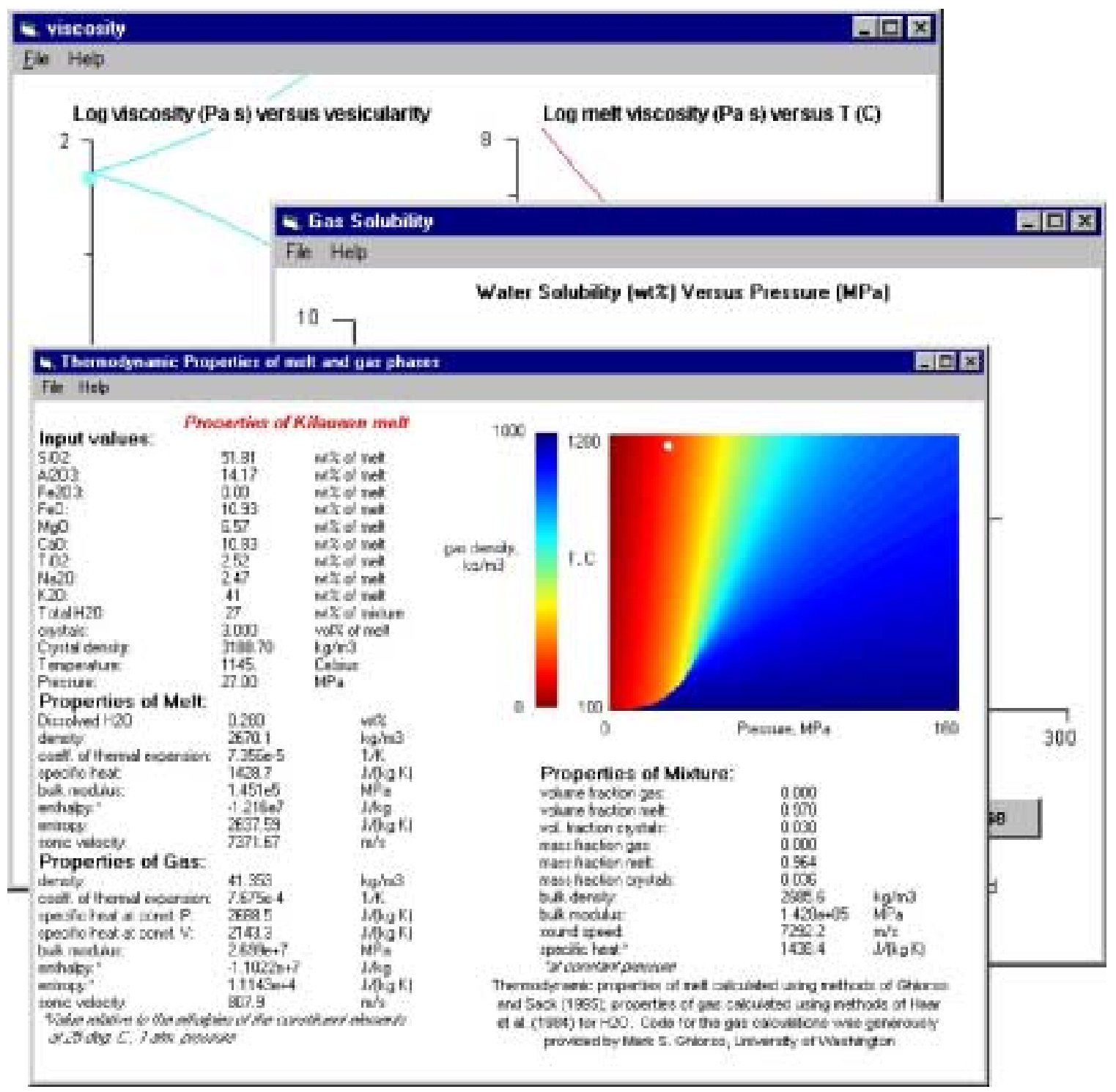

Figure 11: windows for thermodynamic properties, water solubility, and viscosity of melt-gascrystal mixture

- Choosing phenocryst types. In the lower box, you can also choose the dominant type of phenocryst in the melt and its abundance (as a volume percent of the liquidcrystal mixture). By choosing a phenocryst type using the radio buttons, the program will calculate its specific heat and density using relations from Berman (1988).

- You can view the thermodynamic properties, the gas solubility in the melt, and the mixture viscosity by clicking the appropriate command buttons. These command buttons will open additional windows (Fig. 11) with plots and output information. 


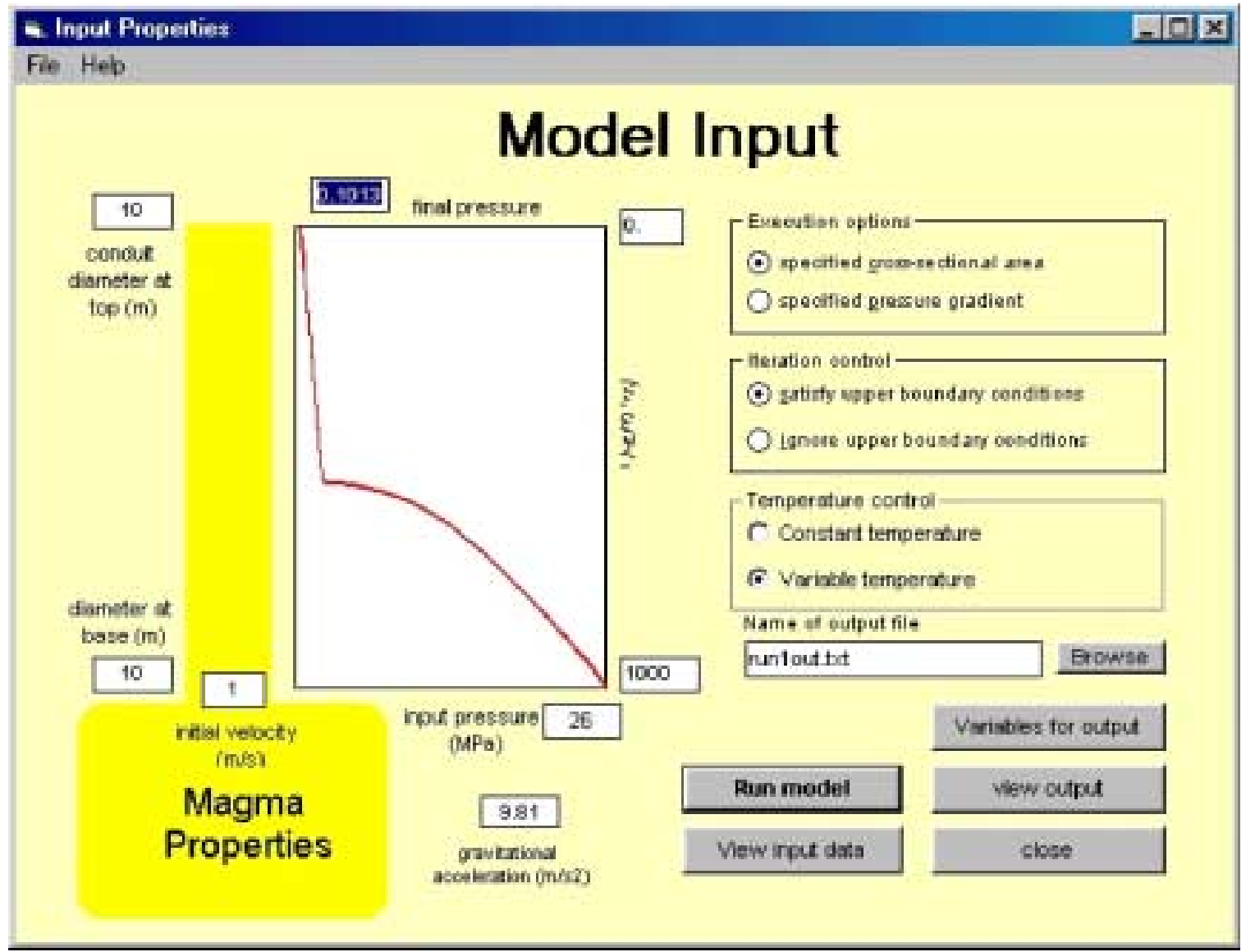

Figure 12: Window for conduit properties

\section{Specifying conduit properties}

By clicking on the "conduit properties" button in the Magma composition window, a new window opens (Fig. 12) from which you can specify properties of the conduit. The following is a list of variables and their effects on the model. Their effects are described in greater detail in the section "RUNNING THE MODEL FROM THE COMMAND LINE".

Execution options. The conduit model calculates flow properties in the conduit using one of two assumptions: (1) The cross-sectional area of the conduit is specified as input to the program, and the program determines the pressure profile; or (2) the pressure profile is specified as input, and the model finds the conduit geometry that produces that pressure profile. By clicking on one of the radio buttons in the Conduit Properties option box on the upper right, you are choosing among those options.

Iteration control. Normally, if the conduit's cross sectional area is specified, the conduit adjusts the input velocity at the base of the conduit until either (1) the velocity at the top of the conduit equals the sonic velocity (choked flow), or (2) the pressure at the top of the conduit equals that specified in the text box of this window. By checking the "ignore upper boundary conditions" radio button in the Iteration Control option box, the program will ignore the upper boundary conditions; it will simply calculate a single run up the conduit, using the input velocity provided. 
Temperature control. Conflow is capable of calculating adiabatic temperature changes within the conduit as a result of shear heating, gas expansion, and gas exsolution. By clicking the "Constant temperature" radio button in the Temperature Control option box, you can convert the program to isothermal calculations. Isothermal calculations are somewhat faster than those that consider adiabatic temperature changes.

Depth, pressure, and gravitational constant. Normally, the pressure and depth at the top of the conduit are set to $0.1013 \mathrm{MPa}(1 \mathrm{~atm})$ and 0 meters, respectively; but you can change these if you prefer to model only a section of the conduit, not ending at the ground surface. Similarly, the gravitational constant and pressure at the top of the conduit can be changed to model eruptions on other planets. The depth at the base of the conduit can be considered the depth immediately above a magma chamber, though this assumption is not necessary. Any depth above a magma chamber can be used as a starting point for the model. The pressure at the base of the conduit is considered by many modelers to be near the lithostatic pressure at that depth (the lithostatic pressure gradient is usually about $20-25 \mathrm{MPa} / \mathrm{km}$ ). In reality, the magma pressure could vary by tens of percent from the lithostatic pressure depending (among other things) on the degree of anisotropy of in the principle stresses of the host rock, the conduit shape, and the rock strength.

Input velocity. In cases where the user specifies the conduit geometry and requires that the upper boundary condition be satisfied, the program uses the input velocity specified in this text box as the starting point of an iterative sequence. In successive model runs it adjusts the input velocity until either (1) the velocity at the top of the conduit is sonic (choked flow); or (2) the pressure at the top of the conduit matches the final pressure specified.

Name of output file. The program will generate a long output file whose name can be specified in this text box. The file will be in normal ASCII format but needn't have the .txt suffix that designates it as a text file.

Variables for output. By clicking on this command button, you open a new window in which you can specify the calculated flow properties (up to seven) to be written to the output file, and which properties (up to four) will be plotted. If you have already run previous models during this programming session, this button will be disabled so that output variables will be consistent from one run to another.

Running the model.

By clicking the "Run model" command button, you run the numerical model for conduit flow, using the input values that were defined in this window and the Magma composition window. The numerical model opens a DOS window (Fig. 13) and writes out intermediate results to the screen as it determines a solution. The meaning of the information written to the screen during execution is described in the section "Model Execution." 


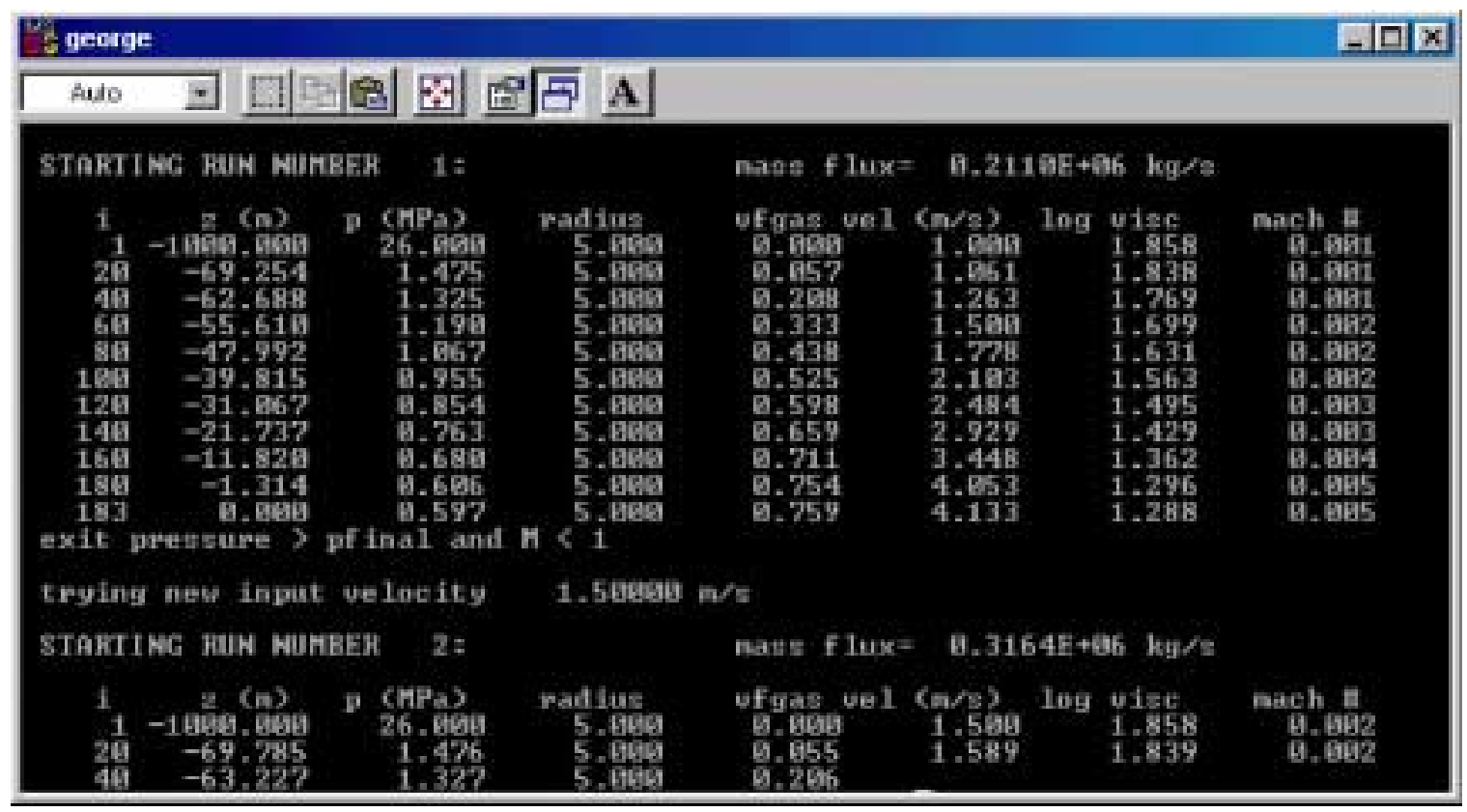

Figure 13: DOS window that opens when the conduit model is launched.

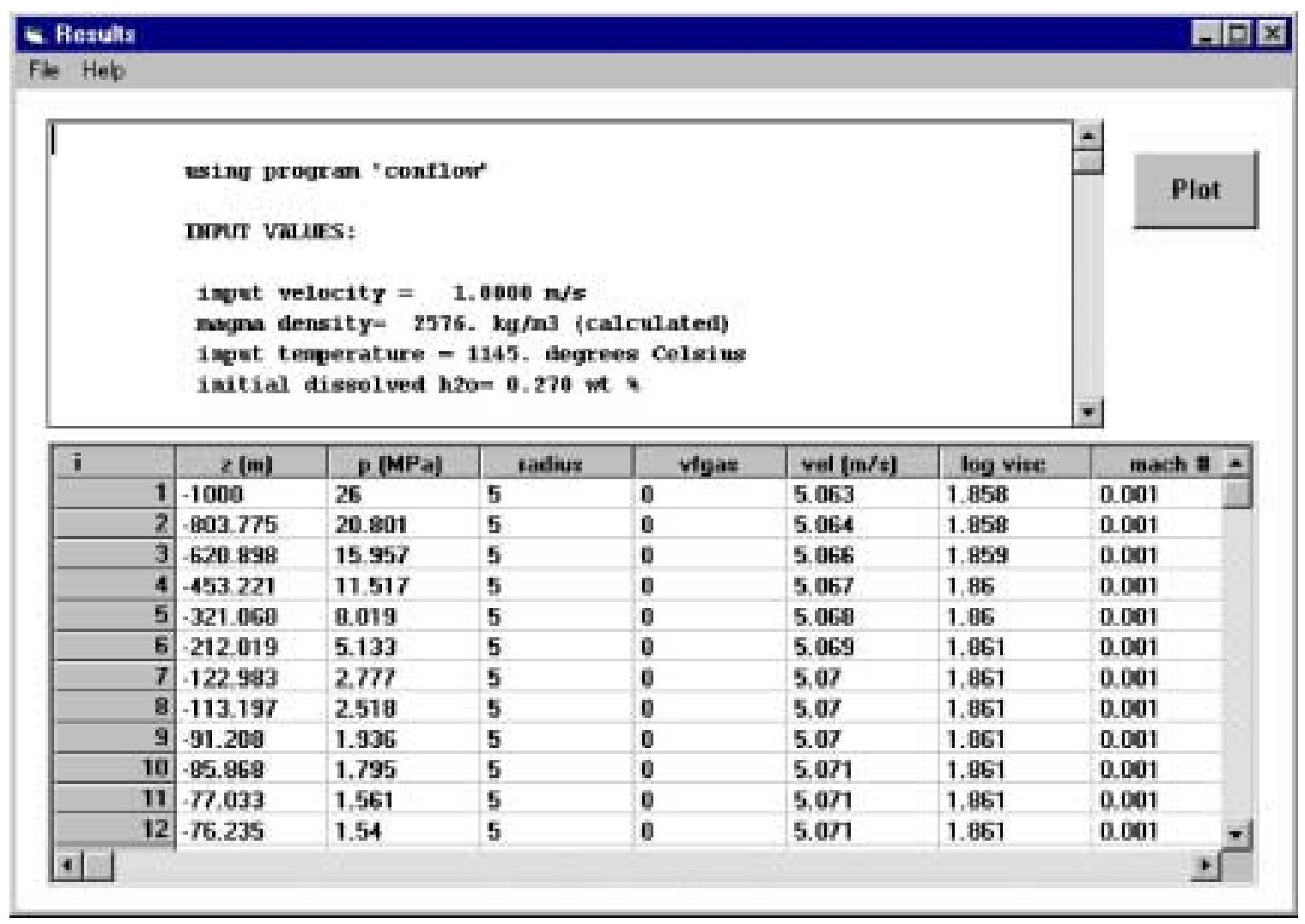

Figure 14: Window displaying output to model. 


\section{Viewing output}

Once the model has finished and the DOS window has closed, the output will be written as text to the file given in the "name of output file" text box. You can view the output data in tabular form by clicking the "view output" command button. It will bring up a new window (Fig. 14) showing a summary of the input conditions and results of iterative model runs shown in the upper text box, and a table of the final flow properties, as a function of depth, in the lower spreadsheet.

\section{Plotting output}

By pressing the plot command button in the results window, a new window (Fig. 15) will appear with plots of the variables that were chosen in the output variables window, accessed through the command button on the Input Properties window. If you executed any other model runs since opening conflow, those model runs will also be plotted for comparison. An explanation of the abbreviations used for $\mathrm{x}$-axis labels is provided under Help >> more info. You can label the plot and print it out if you wish.

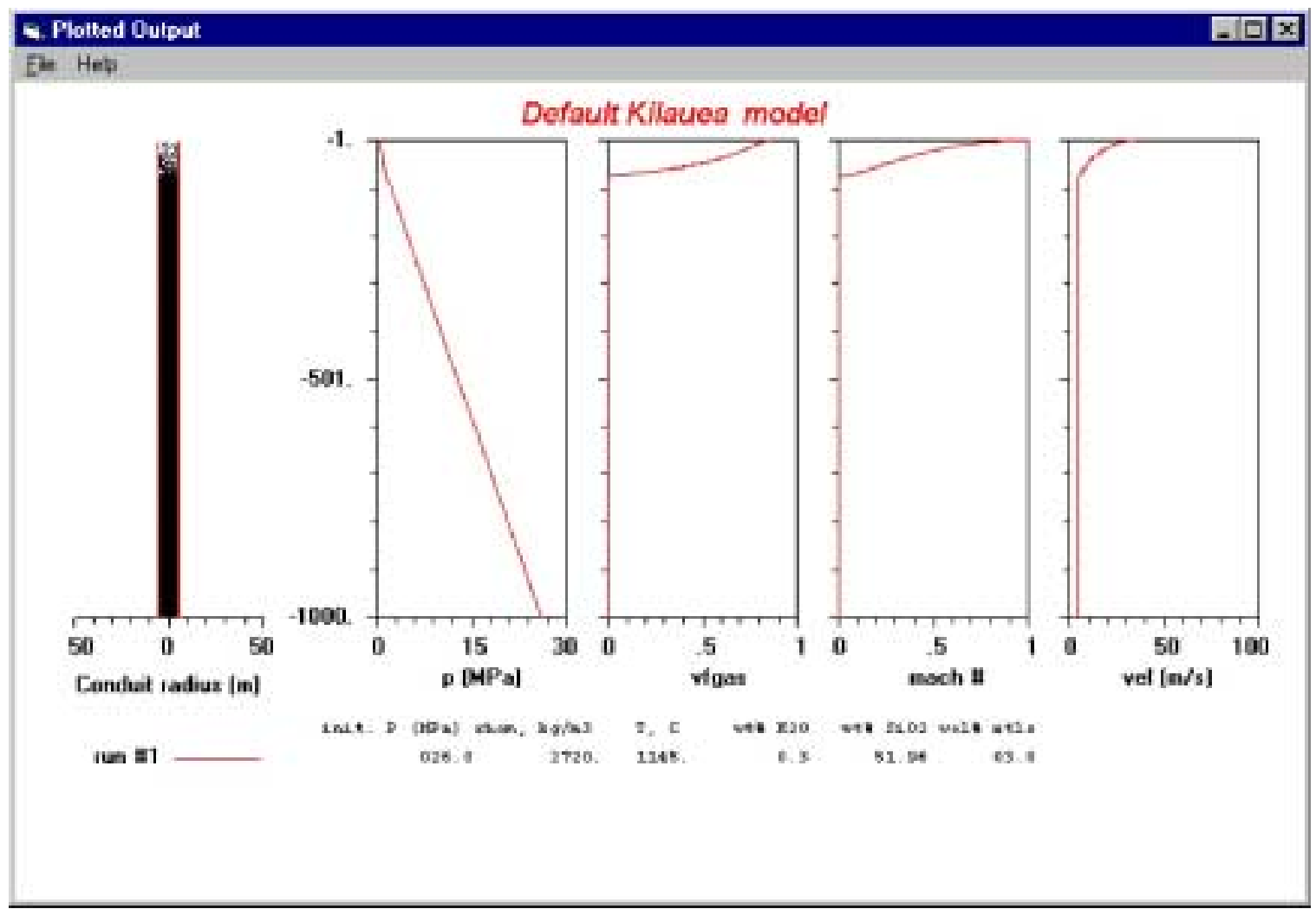

Figure 15: Window displaying plotted output.

Running the Model from the Command Line

The graphical and interactive version of this program that runs on Windows-based computers calls a simple Fortran program (named confort.exe) from the DOS 
command line. The program confort.exe resides in the same directory as Conflow.exe (usually c:Iprogram files\Conflow). Confort.exe can also be operated from a DOS command line by opening a DOS window, moving to the directory containing confort.exe, and typing "confort". Compiled versions of this program will also be posted in the ftp directory Elektra.wr.usg.gov/Ftp_Access/Pub/lgmastin/Conflow, which will run on other operating systems.

When executed, the program reads from the ASCII input file conin, which resides in the same directory and can be edited using any text editor. The file appears as follows:

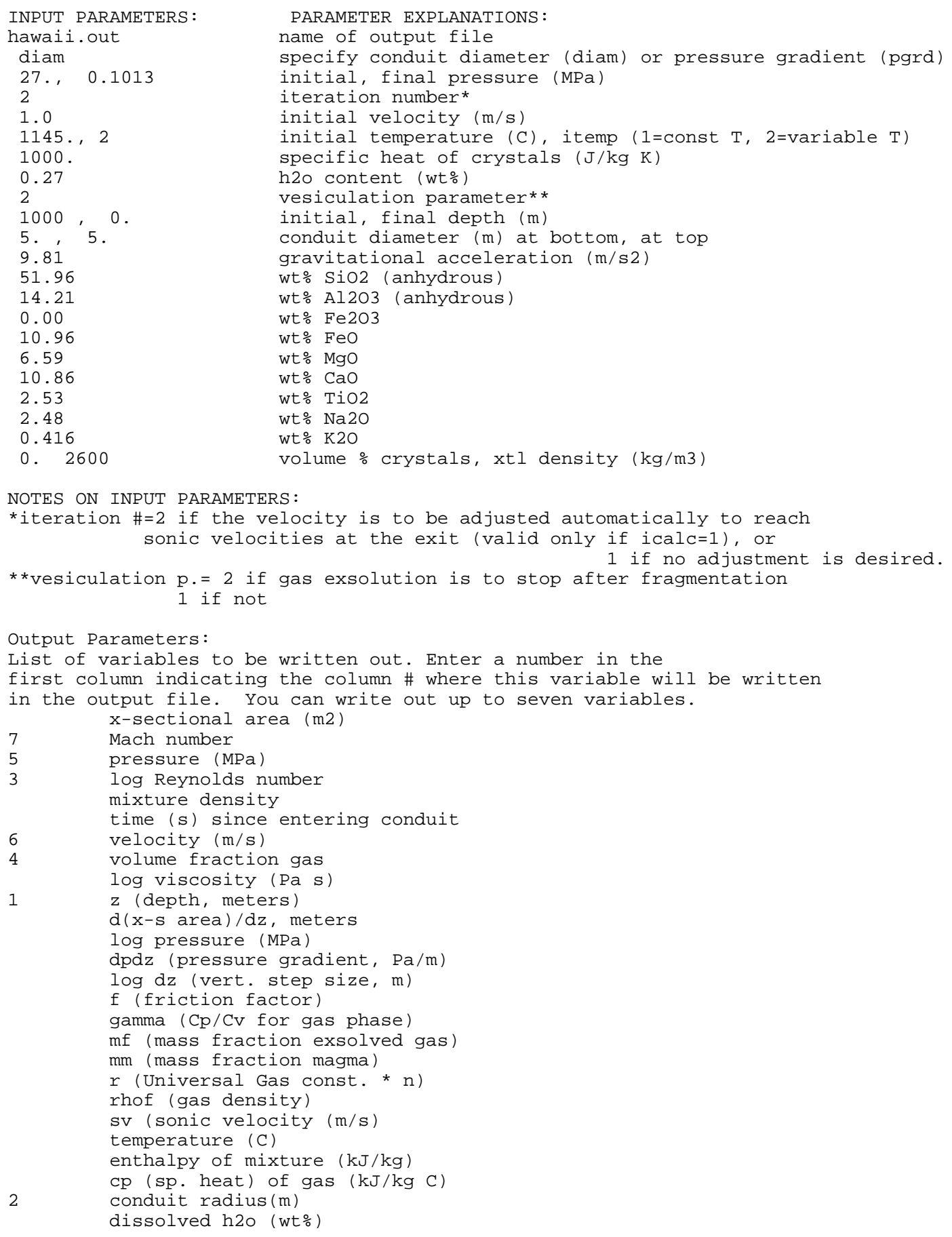


The twenty-one lines following the first line of the file contain the input parameters on the left side. Those parameters are read using unformatted read statements, so they can be changed without worrying about column numbers or number of decimal places. Just be careful not to add or delete any lines while editing the file. All variables are double precision, real numbers, with the exceptions of the vesiculation parameter, the iteration number, and itemp, which are integers, and the parameter on the second line, which is a 4-character variable ("diam" or "pgrd").

The right- hand side of each line explains (briefly) what each parameter represents. Parameter explanations that require somewhat more information are followed by asterisks, with supplemental information on following lines. Although most parameters are self-explanatory, the following parameters require more detailed information:

Specifying conduit diameter or pressure gradient

The second line of the input file specifies which option to use when running the program. If "diam" is specified, the program assumes a constant conduit diameter and calculates a pressure profile. If "pgrd" is specified, constant pressure gradient is assumed and the program calculates the profile in cross-sectional area that would produce such a pressure gradient.

Pressure at base and top of conduit

This parameter is used only if the conduit diameter is specified (instead of the pressure gradient). There is no real upper limit to the maximum input pressure that can be used, but the lower limit is constrained by the weight (per unit area) of the magma in the conduit. If the input pressure is less than that weight per unit area, the magma will not erupt. In such a case, the model will reach $\mathrm{p}=1 \mathrm{~atm}$ at some depth below the surface. If the model is set to iterate until $\mathrm{p}=1 \mathrm{~atm}$ or $M=1$ at the surface, it will decrease the velocity at the base of the conduit and try another run. If, after several iterations, the initial velocity drops below $0.001 \mathrm{~m} / \mathrm{s}$ and $\mathrm{p}=1 \mathrm{~atm}$ is still reached below the ground surface, the program returns the following message to the screen:

pressure insufficient to produce eruption

and writes the results of the last run (in which initial velocity $=0.001 \mathrm{~m} / \mathrm{s}$ ) to the output file. The following table indicates the minimum pressures that will produce upflow for various conduit lengths for Kilauean basalt, given other input parameters shown in the example input file:

$\begin{array}{cc}\text { depth at base of conduit } & \text { minimum pressure for upflow (MPa) } \\ 100 \mathrm{~m} & 0.17 \\ 200 & 0.35 \\ 500 & 4.35 \\ 1000 & 17.1 \\ 3000 & 71.6\end{array}$


For silicic melts, minimum pressures that will still produce an eruption are negligible (less than $5 \mathrm{MPa}$ at the base of a 5-km long conduit for Pinatubo magma, for example; Fig. 12). In reality, significantly higher pressures would be necessary at these depths to drive eruptions, since gas escape at low magma velocities would densify the magma column and increase its weight.

If the combination of input pressure and $\mathrm{H}_{2} \mathrm{O}$ content of the melt are such that vesicularity at the base of the conduit exceeds $75 \%$, the program assumes that the melt has already fragmented before entering the base of the conduit.

In general, the pressure at the top of the conduit is specified to be 1 atmosphere $(0.1013 \mathrm{MPa})$. However this program gives the user the option to specify other output pressures, which may be useful under three circumstances: (1) when modeling eruption dynamics on other planets; (2) when modeling magma flow through a particular depth interval whose top does not lie at the surface; or (3) modeling an eruption that vents to the sea floor, the floor of a lake, or of a lava pond. The option of variable final pressure allows the user to model a complicated conduit geometry by breaking the conduit into sections and modeling each depth interval separately.

If option 2 (pressure gradient specified) is chosen, the pressure within the conduit is assumed to vary linearly between the initial and final values. The pressure gradient is the difference between these pressures, divided by the length of the conduit. The conduit's cross-sectional area is adjusted, along with flow properties, to fit this gradient. Some models of conduit flow (e.g., Wilson and Head, 1981; Dobran, 1992) assume that the pressure gradient driving magma flow is the gradient $\rho_{c r} g$, determined by the country rock density, $\rho_{c r}$. In those programs, if a country rock density of $2300 \mathrm{~kg} / \mathrm{m}^{3}$ is used as input, the program calculates a pressure gradient of $\rho_{c r} g=2.25 \times 10^{4} \mathrm{~Pa} / \mathrm{m}$, and a pressure at the base of a $3-\mathrm{km}$-long conduit of $1.013 \times 10^{5} \mathrm{~Pa}+(3000 \mathrm{~m})\left(2.25 \times 10^{4} \mathrm{~Pa} / \mathrm{m}\right)=$ $6.78 \times 10^{7} \mathrm{~Pa}$, or $67.8 \mathrm{MPa}$. In fact, far-field horizontal stress gradients may be as important as the lithostatic pressure gradient in controlling the flow up the conduit. In the program Conflow, pressures at the top and bottom of the conduit are given directly as input to the program rather than a rock density from which a pressure gradient is calculated.

There is one caveat when considering the input value for pressure. If the pressure gradient in the conduit is less than that due to the weight of the magma-gas mixture at the base of the conduit, the magma may not flow upward. In that case, the following error message will appear:

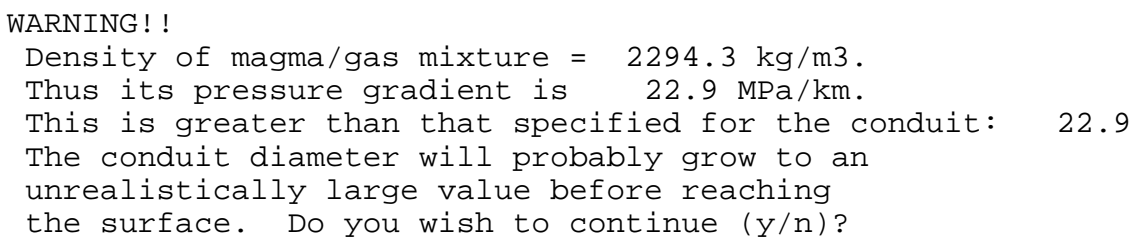

The program will increase the in cross-sectional area with depth to match the specified pressure gradient; but the pressure gradient nevertheless not be reached without expanding the conduit diameter to an unrealistically large value. If this happens, you will see the following error message: 
Conduit diameter or dadz is unrealistically large.

Program stopped.

You will have to increase the pressure gradient (by either increasing the initial pressure or decreasing the final pressure) and try again.

Iteration number

If this number is 1 and the conduit diameter (rather than pressure gradient) is specified, the velocity will not be adjusted to match the exit boundary conditions. The program calculates a single run up the conduit and writes out the results without attempting to match the exit conditions to the boundary conditions. If the velocity of the mixture reaches the sonic velocity before the calculations reach the top of the conduit, the program stops at that depth. The same is the case if the pressure drops below atmospheric before the calculations reach the surface.

Tolerance levels. If the iteration number $=2$, the program will iterate until the output pressure is between 0.1012 and $0.1014 \mathrm{MPa}(1 \mathrm{~atm}=0.1013 \mathrm{MPa})$. For the $M=1$ boundary condition, the program iterates until $M=1$ is reached (to double-precision accuracy) less than 2 meters below the surface.

Lack of Convergence. On a few occasions, the program may have some difficulty reaching a solution within the tolerance levels specified above. Sometimes this problem is due to the fact that final exit pressures or velocities are extremely sensitive to the input velocity, and very slight changes in input velocity (usually less than $10^{-4} \mathrm{~m} / \mathrm{s}$ ) cannot produce an acceptable result. In such a case, the program stops, writes out the results of its best run, and prints the following message to the screen:

limit of resolution reached

On more rare occasions, the program just won't converge at all. If this happens, a slight change to an input parameter will usually solve the problem.

Initial velocity

In option 1 (where conduit diameter is specified), if the iteration number=1, the velocity is adjusted until the output pressure $=1 \mathrm{~atm}$ or the output velocity=sonic velocity of the mixture. Under these circumstances, the initial input velocity is only the starting point of the iteration sequence. If option 2 is specified, or the iteration number $=2$, then the initial velocity is used for the final solution.

Initial temperature

Used to calculate viscosity of magma, specific volume of the gas phase (using the Haar et al. gas relationships), and enthalpy of the magma-gas mixture. The initial temperature is given in degrees Celsius.

$\mathrm{H}_{2} \mathrm{O}$ content

This is the amount of $\mathrm{H}_{2} \mathrm{O}$ (both dissolved and exsolved) in the erupting mixture, in weight percent. we have successfully used water contents from $0 \%$ to $100 \%$, though the 
model is not designed to handle those end members. Real values of gas entrained in melt during plinian, sub-plinian, or lava-fountain eruptions rarely exceed several percent.

\section{Vesiculation parameter}

In the uppermost several tens of meters of the conduit, when vesicularity and eruptive velocities are high, gas exsolution rates may not keep pace with the rate of depressurization. If the vesiculation parameter is set to 2 , gas exsolution is no longer computed once the magma fragments (though gas expansion due to decompression is still calculated). If the vesiculation parameter $=1$, gas exsolution is also calculated at all vesicularities. At the base of the conduit, the dissolved water content of the melt is assumed to be at equilibrium, whether the magma has fragmented or not.

Initial, final depth

The depth of the base and top of the conduit, in meters. Numerically, the program can handle any arbitrary starting depth, from several kilometers (or more), essentially up to the ground surface. If unusually shallow starting depths are used, the mixture will already be highly vesiculated, possibly fragmented. If the vesicularity at the base of the conduit exceeds $75 \%$, the program assumes that the melt has already fragmented.

Conduit diameter at base, at top

Under option 1 (where conduit diameter is specified), these variables give the diameter of the conduit at the base and top, respectively. The program assumes that the conduit's diameter varies linearly between these values. If option 2 (pressure gradient) is specified, the program reads only the diameter at the base of the conduit. The diameter at the top is calculated.

\section{Gravitational acceleration}

This is normally $9.81 \mathrm{~m} / \mathrm{s}^{2}$ for eruptions on Earth. It can be adjusted for eruptions on other planets.

Magma composition

The melt composition is given in weight percent of the major oxides in an anhydrous melt. These values are used to calculate viscosity, density, gas solubility, specific heat, and enthalpy of the melt. The relations that calculate those properties are calibrated for the range of silicate melts found in nature. It is not known how valid these properties are when extended outside the range of natural silicate melts. When reading the compositional data, the program checks to see that they add up to $100 \%$. If the total differs by more than $0.1 \%$ from $100 \%$, you will receive the following error message:

total of component oxides does not equal $100 \%$ Adjust automatically? $(\mathrm{y} / \mathrm{n})$

If you enter 'y', the program will adjust the weight percent of each oxide proportionately so that the total equals $100 \%$. If you enter ' $n$ ', the program will stop and you must edit the input file and try again. 


\section{Specifying the Variables to be W ritten as Output}

The last 37 lines of the input file contain the names of variables that can be written to the output file for each depth. You must specify seven variables to be written out. For each variable to be written out, enter a number at the beginning of the appropriate line corresponding to the column in the output file where this variable will appear. In the example input file above, the depth (z) is to be written in the first column of the output table; temperature in the second, velocity in the third, $\log$ viscosity in the fourth, and so on.

You must specify output variables for seven columns of output. If you neglect to specify output for a given column (e.g., column 1), you will receive an error message like the following:

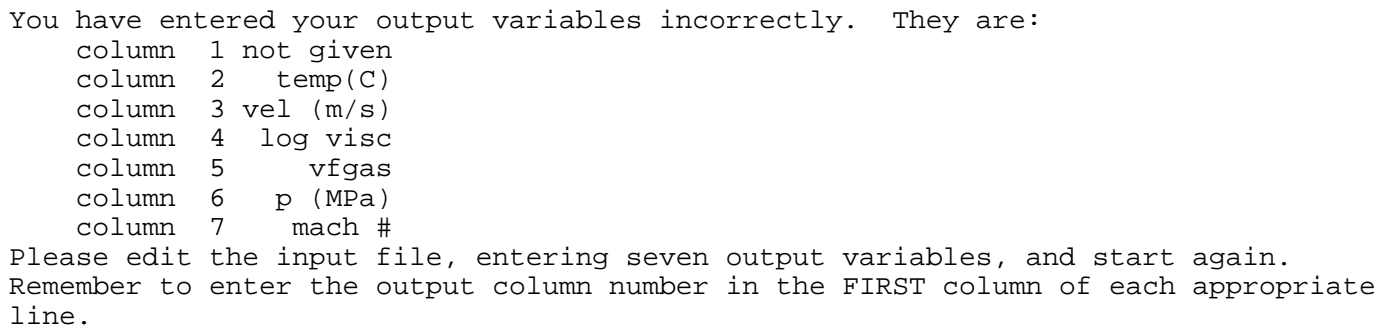

You can also receive this error message if the column number specified is not entered as the FIRST character in the appropriate line of the input file (i.e. if the column number is preceded by one or more spaces). Alternatively, if you specify the same column number for two or more output variables, you may receive an error message as follows:



\section{M odel Execution}

The program can be executed by moving to the directory where it resides and typing "confort" on the command line. (If your computer uses Microsoft Windows $\mathrm{s}$, you should open a DOS window before executing the program). As long as the input file conin, is in the same directory as the executable file, the program should be able to find it. Two examples of program execution are given below: one using option 1 (specified conduit diameter), the other using option 2 (constant pressure gradient).

Example using option 1

Once the program is started, it will write out the input values to the DOS window as follows:

using program "Conflow"

\footnotetext{
${ }^{5}$ The use of trade names is not intended to be an endorsement of those products.
} 


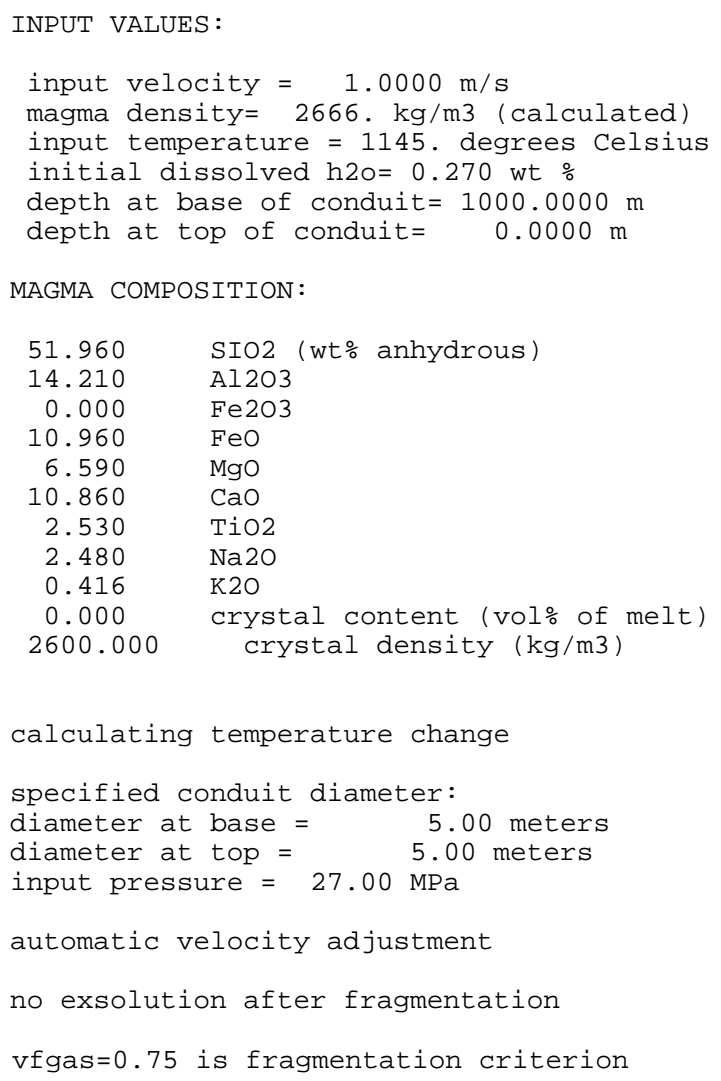

These are the same input parameters specified in the sample input file above. For this run, the conduit diameter is taken to be constant and the program adjusts the input velocity until $M=1$ or $p=1$ atm at the surface.

Next, the program will begin calculating flow properties from the bottom to the top of the conduit. The output to the screen at this point in execution is:

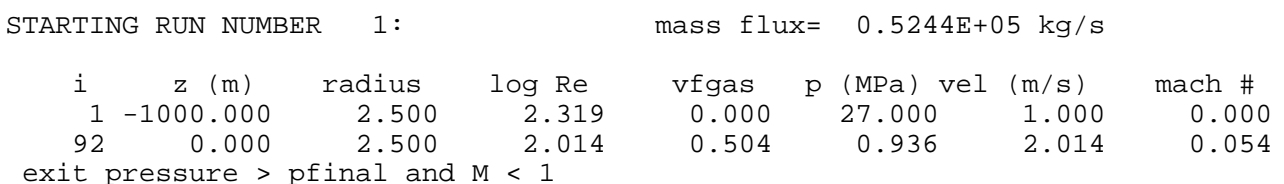

After writing out the mass flux calculation, the program has written a line of output variables calculated at the bottom of the conduit, and a second line at the final depth. On the last line, the program notes that the final exit pressure exceeds $1 \mathrm{~atm}$ and the Mach number is less than 1 . The program therefore increases the input velocity and computes a second run, writing the output as follows:

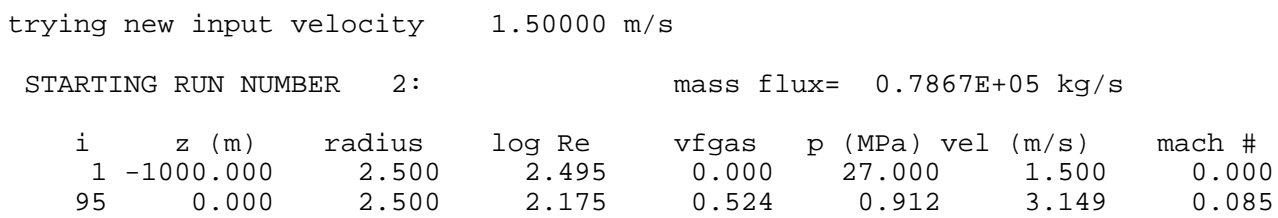


Again, the final exit velocity exceeded 1 atm and the final Mach number is less than 1 . After adjusting the input velocity again, a third run is attempted:

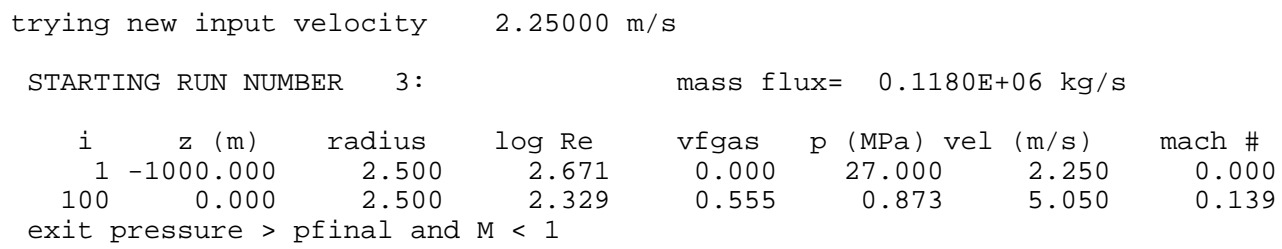

After increasing the input velocity three more times, Conflow exceeds Mach 1 before reaching the surface:

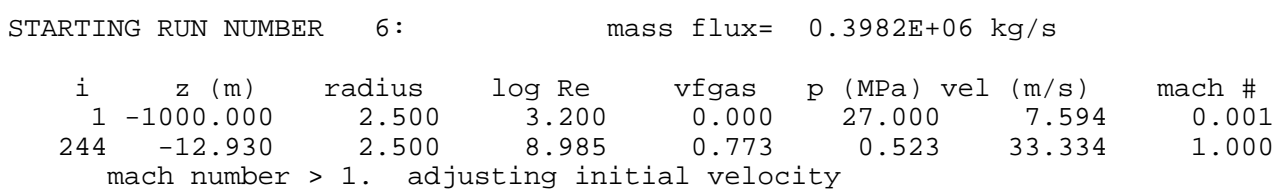

After several more adjustments to the input velocity, Conflow final reaches an acceptable solution:

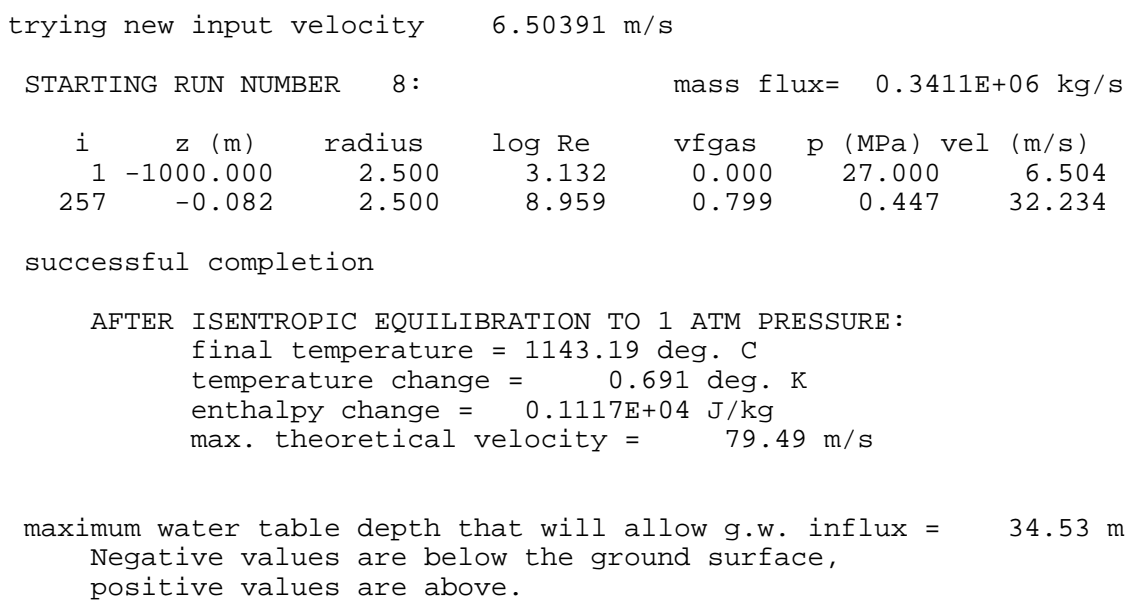

This output shows that, during the last run, the Mach number reached 1 at a depth of $0.082 \mathrm{~m}$, well within the tolerance limit of $2 \mathrm{~m}$.

In all runs where the Mach number=1 when the mixture exits the conduit, the pressure will be greater than 1 atmosphere. After the mixture leaves the conduit, it will continue to accelerate and cool adiabatically as it drops to atmospheric pressure. If we assume that these processes take place isentropically (i.e. without friction), we can calculate a maximum theoretical velocity and a maximum amount of adiabatic cooling. These calculations are done by assuming that all excess enthalpy in the mixture is converted to kinetic energy during expansion (Mastin, 1995a). Procedures for this calculation are explained in Appendix D. The output written above indicates that the velocity could theoretically accelerate from $32.234 \mathrm{~m} / \mathrm{s}$ to $79.49 \mathrm{~m} / \mathrm{s}$ after leaving the vent. During expansion, the mixture would theoretically cool by about a half degree Celsius. 
A final calculation is made of the depth of the water table required to produce groundwater influx during the eruption. The calculation is made by numerically drawing a hydrostatic pressure curve that is just tangent to the pressure profile in the conduit. The depth ("WT" in Fig. 16) at which the hydrostat reaches one atmosphere gives the water table depth listed above. If subsurface water pressures follow the hydrostatic curve, then a water table at this depth or higher would create hydrostatic pressures sufficient to drive water into the conduit. Whether water enters in sufficient quantities to produce explosive, phreatomagmatic interactions, depends on factors such as rock permeability, that are not considered here. This model also does not consider other important processes that take place once water enters a conduit and mixes with magma, possibly including steam expansion, brittle fragmentation of melt caused by high strain rates, and fuelcoolant interactions.
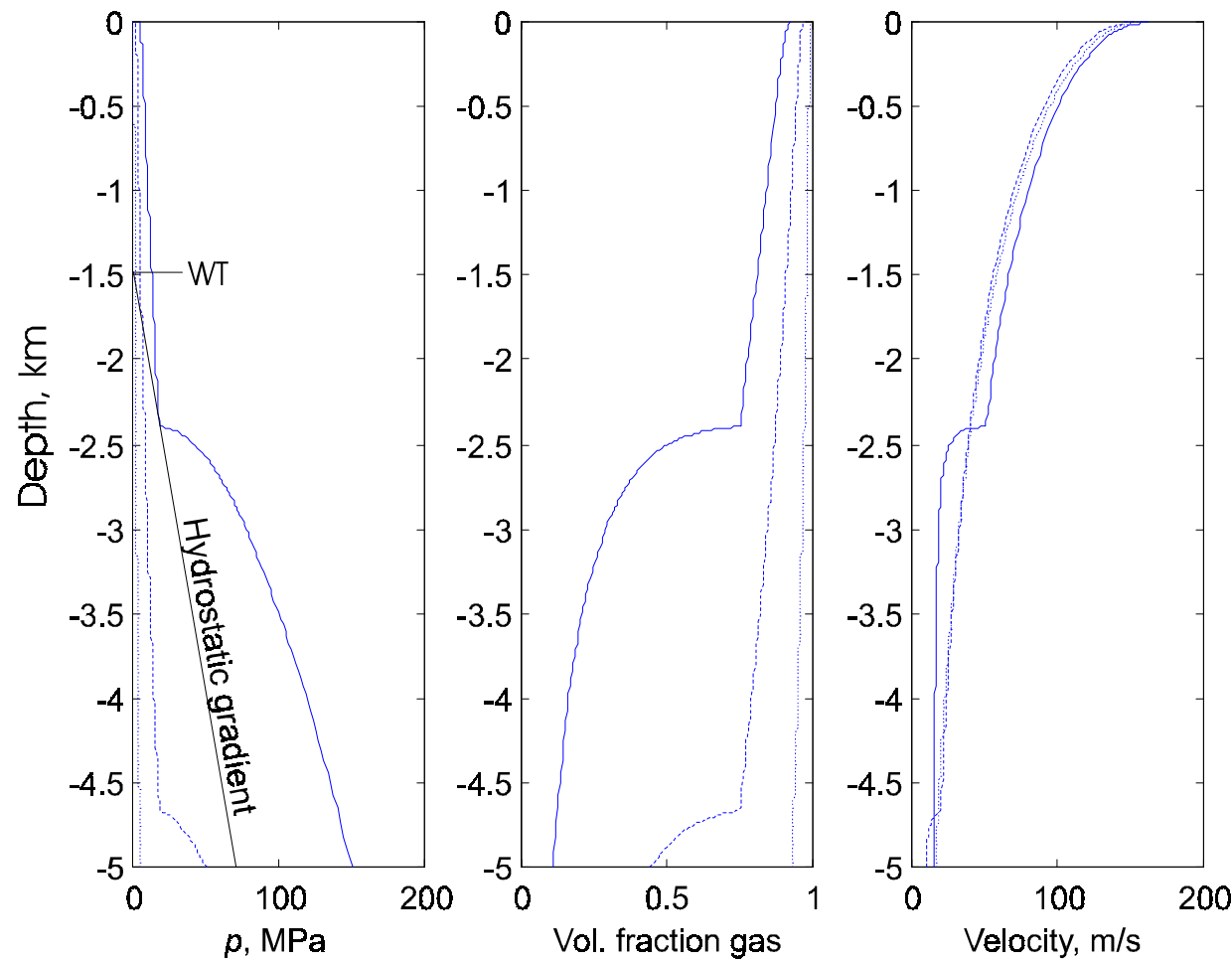

Figure 16: flow properties in a 5-km long, 50-m diameter eruptive conduit containing Pinatubo magma at $780^{\circ} \mathrm{C}$, with $6 \mathrm{wt} \%$ water, for three different input pressures at the base of the conduit. The plot illustrates (a) that extremely low input pressures can still generate eruptions, and (2) that the final eruptive velocity is extremely insensitive to changes in input pressure. The heavy solid line illustrates a hydrostatic gradient that is just tangent to the solid pressure profile. The y value of this line at $p=1$ atm (labeled "WT") gives the maximum water-table depth of a normally pressured groundwater system in which water pressures would be sufficient to drive water into the conduit.

Program output. Once the program completes its calculations, open the output file and you will see the following table (already described):

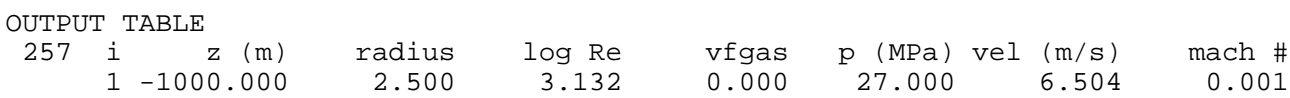




\begin{tabular}{|c|c|c|c|c|c|c|c|}
\hline 2 & -798.867 & 2.500 & 3.132 & 0.000 & 21.601 & 6.506 & 0.001 \\
\hline 3 & -612.370 & 2.500 & 3.132 & 0.000 & 16.597 & 6.509 & 0.001 \\
\hline 4 & -459.127 & 2.500 & 3.131 & 0.000 & 12.486 & 6.510 & 0.001 \\
\hline 5 & -315.245 & 2.500 & 3.131 & 0.000 & 8.626 & 6.512 & 0.001 \\
\hline & - & & & & & & \\
\hline & & & & & & & \\
\hline 257 & -0.082 & 2.500 & 8.959 & 0.799 & 0.447 & 32.234 & 1.000 \\
\hline
\end{tabular}

The variables are listed in this table as specified in the input file. The second line gives the number of data points written out (257), followed by 257 lines for depths extending from the base to the top of the conduit.

Example using option 2 (specifying pressure gradient)

For the second example, we've taken the sample input file and changed it slightly so that the pressure gradient ("pgrd") is specified, and the conduit radius (instead of log viscosity) is written out to column 4 of the output file. After typing Conflow to start the program, the program echoes the input variables, then prints the following lines for the model run:

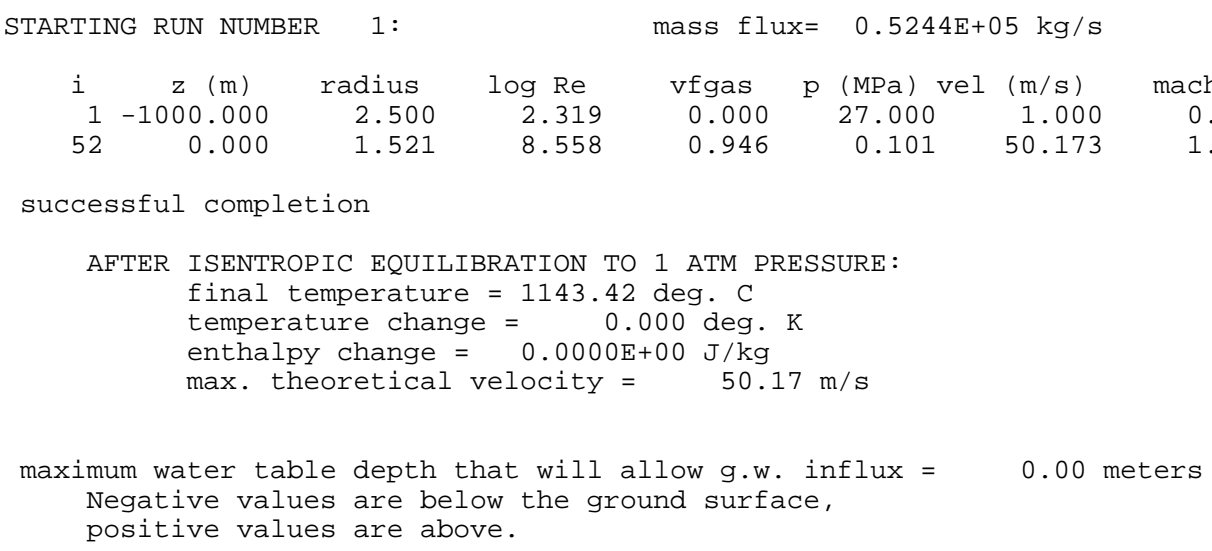

Note that the program required only a single run up the conduit, because the $p=$ pfinal boundary condition is automatically satisfied at the final depth. Note also that the Mach number (1.839) at the conduit exit is much greater than 1 , as it can be with a variable conduit geometry. Similarly, the exit velocity $(50.17 \mathrm{~m} / \mathrm{s})$ is equal to the maximum theoretical velocity because the erupting mixture has fully equilibrated with atmospheric pressure by the time it reaches the surface. The maximum water-table depth that will allow groundwater influx is zero, because the surface is the only place where the two pressure curves (the hydrostat and the conduit pressure curve) intersect.

\section{Closing Comments}

This report is intended to give a concise summary of the underlying principles of this program and of its potential applications. It will probably evolve with time into something more complicated and, hopefully, more realistic. If you intend to make extensive use of this program or would like to find out about new revisions, you are encouraged to contact the author at (360) 993-8925 (e-mail at \gmastin@ usgs.gov) 


\section{References}

Alidibirov, M.A., 1994, A model for viscous magma fragmentation during volcanic blasts: Bulletin of Volcanology, v. 56, p. 459-465.

Alidibirov, M., and Dingwell, D.B., 1996, Magma fragmentation by rapid decompression: Nature, v. 380, p. 146-148.

Bagdassarov, N.S., and Dingwell, D.B., 1992, A rheological investigation of vesicular rhyolite: Journal of Volcanology and Geothermal Research, v. 50, no. 2, p. 307-322.

Bansal, N.P., and Doremus, R.H., 1986, Handbook of glass properties. Academic Press, New York, London, pp. 680.

Barmin, A.A., and Melnik, O.E., 1993, Eruption dynamics of high-viscosity gas-saturated magmas: Iz. Ros. Akad. Nauk. Mekh. Zhidk. Gaza, v. 2, p. 49-60.

Berman, R.G., 1988, Internally consistent thermodynamic data for minerals in the system $\mathrm{Na}_{2} \mathrm{O}-\mathrm{K}_{2} \mathrm{O}-\mathrm{CaO}-\mathrm{MgO}-\mathrm{FeO}-\mathrm{Fe}_{2} \mathrm{O}_{3}-\mathrm{Al}_{2} \mathrm{O}_{3}-\mathrm{SiO}_{2}-\mathrm{TiO}_{2}-\mathrm{H}_{2} \mathrm{O}$ : Journal of Petrology, v. 29, p. 445-522.

Bird, R.B., Stewart, W.E., and Lightfoot, E.N., 1960, Transport Phenomena: New York, John Wiley and Sons, $780 \mathrm{p}$.

Buresti, G., and Casarosa, C., 1989, One-dimensional adiabatic flow of equilibrium gasparticle mixtures in long vertical ducts with friction: Journal of Fluid Mechanics, v. 203, p. 251-272.

Burnham, C.W., and Davis, N.F., 1971, The role of $\mathrm{H}_{2} \mathrm{O}$ in silicate melts. I. P-V-T relations in the system $\mathrm{NaAlSi}_{3} \mathrm{O}_{8}-\mathrm{H}_{2} \mathrm{O}$ to 10 kilobars and $1000^{\circ} \mathrm{C}$ : American Journal of Science, v. 270, p. 54-79.

Burnham, C.W., and Davis, N.F., 1974, The role of $\mathrm{H}_{2} \mathrm{O}$ in silicate melts: II. Thermodynamic and phase relations in the system $\mathrm{NaAl}_{3} \mathrm{SiO}_{8}-\mathrm{H}_{2} \mathrm{O}$ to 10 kilobars, $700^{\circ}$ to $1100^{\circ} \mathrm{C}$ : American Journal of Science, v. 274, p. 902-940.

Cashman, K.V., Sturtevant, B., Papale, P., and Navon, O., 2000, Magmatic Fragmentation, in Sigurdsson, H., et al. [eds.], Encyclopedia of Volcanoes, Academic Press, San Diego, p. 421-430.

Dingwell, D.B., Romano, C., and Hess, K.-U., 1996, The effect of water on the viscosity of a haplogranitic melt under P-T-X conditions relevant to silicic volcanism: Contributions to Mineralogy and Petrology, v. 124, p. 19-28.

Dixon, J.E., Stolper, E.M., and Holloway, J.R., 1995, An experimental study of $\mathrm{H}_{2} \mathrm{O}$ and carbon dioxide solubilities in mid-ocean ridge basaltic liquids. Part I: Calibration and solubility results: Journal of Petrology, v. 36, p. 1607-1631.

Dobran, F., 1992, Nonequilibrium flow in volcanic conduits and application to the eruptions of Mt. St. Helens on May 18, 1980 and Vesuvius in AD 79: Journal of Volcanology and Geothermal Research, v. 49, p. 285-311.

Eichelberger, J.C., Carrigan, C.R., Westrich, H.R., and Price, R.H., 1986, Non-explosive silicic volcanism: Nature, v. 323, p. 598-602.

Eilers, H., 1943, Viscosity-concentration relations of colloid systems in organic solvents: Kolloid-Zeitschrift, v. 102, p. 154-169.

Einstein, A., 1906, Eine neue Bestimmung der Molekül-Dimensionen. Annalen der Physik, v. 19, p. 648-661. 
, 1911, Berichtigung zu meiner Arbeit: "Eine neue Bestimmung der MolekülDimensionen." Annalen der Physik, v. 34, p. 591-591.

Gay, E.C., Nelson, P.A., and Armstrong, W.P., 1969, Flow properties of suspensions with high solids concentrations: AIChE Journal, v. 15, p. 815-822.

Ghiorso, M.S., and Sack, R.O., 1995, Chemical mass transfer in magmatic processes IV: A revised and internally consistent thermodynamic model for the interpolation and extrapolation of liquid-solid equilibria in magmatic systems at elevated temperatures and pressures: Contributions to Mineralogy and Petrology, v. 119, p. 197-212.

Giberti, G., and Wilson, L., 1990, The influence of geometry on the ascent of magma in open fissures: Bulletin of Volcanology, v. 52, p. 515-521.

Haar, L., Gallagher, J.S., and Kell, G.S., 1984, NBS/NRC Steam Tables: New York, Hemisphere Publishing Corporation, 320 p.

Hamilton, D.L., Burnham, C.W., and Osborn, E.F., 1964, The solubility of water and effects of oxygen fugacity and water content on crystallization in mafic magmas: Journal of Petrology, v. 5, p. 21-39.

Hamilton, D.L., and Oxtoby, S., 1986, Solubility of water in albite-melt determined by the weight-loss method: Journal of Geology, v. 94, p. 626-630.

Head, J.W.I., and Wilson, L., 1987, Lava fountain heights at Pu'u 'O'o, Kilauea, Hawaii: Indicators of amount and variations of exsolved magma volatiles: Journal of Geophysical Research, v. 92, no. B13, p. 13715-13719.

Hess, W.R., 1920, Beitrag zur Theorie der Viskosität Heterogener Systeme. Kolloid Zeitschrift, v. 27, p. 1-11.

Hess, K.-U., and Dingwell, D.B., 1996, Viscosities of hydrous leucogranitic melts: A non-Arrhenian model: American Mineralogist, v. 81, p. 1297-1300.

Hoerner, S.F., 1965, Fluid Dynamic Drag: Vancouver, WA, published by the Author.

Holtz, F., Behrens, H., Dingwell, D.B., and Johannes, W., 1995, $\mathrm{H}_{2} \mathrm{O}$ solubility in haplogranitic melts: compositional, pressure, and temperature dependence: American Mineralogist, v. 80, p. 94-108.

Jaupart, C., and Allègre, C.J., 1991, Gas content, eruption rate and instabilities of eruption regime in silicic volcanoes: Earth and Planetary Science Letters, v. 102, p. 413-429.

Jeffrey, D.J., and Acrivos, A., 1976, The rheological properties of suspensions of rigid particles: AIChe Journal, v. 22, p. 417-432.

Kaminski, É., and Jaupart, C., 1997, Expansion and quenching of vesicular magma fragments in Plinian eruptions: Journal of Geophysical Research, v. 102, p. 12187 12203.

Kerr, R.C., and Lister, J.R., 1991, The effects of shape on crystal settling and on the rheology of magmas: Journal of Geology, v. 99, p. 457-467.

Kieffer, S.W., 1981, Fluid dynamics of the May 18 blast at Mount St. Helens, in Lipman, P.W., and Mullineaux, D.R., eds., The 1980 Eruptions of Mount St. Helens, Washington. U.S. Geological Survey Professional Paper 1250, p. 379-400.

- 1984, Factors governing the structure of volcanic jets, in Explosive Volcanism, Inception, Evolution, and Hazards: Washington, D.C., National Academy Press, p. 143-157.

- 1989, Geologic nozzles: Reviews of Geophysics, v. 27, no. 1, p. 3-38. 
Lejeune, A.-M., and Richet, P., 1995, Rheology of crystal-bearing silicate melts: An experimental study at high viscosities: Journal of Geophysical Research, v. 100, no. B3, p. 4215-4229.

Liepmann, H.W., and Roshko, A., 1957, Elements of Gasdynamics: New York, John Wiley and Sons, $439 \mathrm{p}$.

Luhr, J.F., and Melson, W.G., 1997, Mineral and glass compositions in June 15, 1991 pumices: Evidence for dynamic disequilibrium in the dacite of Mount Pinatubo, in Newhall, C.H., ed., Fire and Mud: Seattle, University of Washington Press, p. 733750.

Manga, M., Castro, J., Cashman, K.V., and Loewenberg, M., 1998, Rheology of bubblebearing magmas: Journal of Volcanology and Geothermal Research, v. 87, p. 15-28.

Mangan, M.T., and Cashman, K.V., 1996, The structure of basaltic scoria and reticulite and inferences for vesiculation, foam formation, and fragmentation in lava fountains: Journal of Volcanology and Geothermal Research, v. 73, no. 1-2, p. 1-18.

Mangan, M.T., Cashman, K.V., and Newman, S., 1993, Vesiculation of basaltic magma during eruption: Geology, v. 21, p. 157-160.

Mangan, M.T., and Sisson, T., 1999, Degassing Difficulties in Rhyolite: Triggering Homogeneous Bubble Nucleation [abstr], Fall 1999 AGU Abstracts with Programs, in press.

Marsh, B.D., 1981, On the crystallinity, probability of occurrence, and rheology of lava and magma: Contributions to Mineralogy and Petrology, v. 78, p. 85-98.

Mastin, L.G., 1995a, Thermodynamics of gas and steam-blast eruptions: Bulletin of Volcanology, v. 57, no. 2, p. 85-98. , 1995b, A numerical program for steady-state flow of Hawaiian magma-gas mixtures through vertical eruptive conduits: Vancouver, WA, U.S. Geological Survey Open-File Report 95-756, 46pp.

— 1997, Evidence for water influx from a caldera lake during the explosive hydromagmatic eruption of 1790, Kilauea Volcano, Hawaii: Journal of Geophysical Research, v. 102, no. B9, p. 20093-20109.

— 1999, Conduit pressure and the character of phreatomagmatic eruptions [abstr]: Eos, v. 80, p. F1121.

Moran, M.J., and Shapiro, H.N., 1992, Fundamentals of Engineering Thermodynamics (2nd ed.): New York, John Wiley and Sons, Inc., 804 p.

Neuville, D.R., Courtial, P., Dingwell, D.B., and Richet, P., 1993, Thermodynamic and rheological properties of rhyolite and andesite melts: Contributions in Mineralogy and Petrology, v. 113, p. 572-581.

Nicholls, J., 1980, A simple model for estimating the solubility of $\mathrm{H}_{2} \mathrm{O}$ in magmas: Contributions to Mineralogy and Petrology, v. 74, p. 211-220.

Ochs, F.A.I., and Lange, R.A., 1999, The density of hydrous magmatic liquids: Science, v. 283, p. 1314-1317.

Pal, R., and Rhodes, E., 1989, Viscosity/concentration relationships for emulsions: Journal of Rheology, v. 33, p. 1021-1045.

Papale, P., 1999, Strain-induced magma fragmentation in explosive eruptions: Nature, v. 397, p. 425-428. 
Papale, P., and Dobran, F., 1993, Modeling the ascent of magma during the plinian eruption of Vesuvius in A.D. 79: Journal of Volcanology and Geothermal Research, v. 58, p. 101-132.

Papale, P., Neri, A., and Macedonio, G., 1998, The role of magma composition and water content in explosive eruptions 1. Conduit dynamics: Journal of Volcanology and Geothermal Research, v. 87, p. 75-93.

Parfitt, E.A., and Wilson, L., 1995, Explosive volcanic eruptions IX--the transition between Hawaiian-style lava fountaining and Strombolian explosive activity: Geophysical Journal International, v. 121, p. 226-232.

Pinkerton, H., and Stevenson, R.J., 1992, Methods of determining the rheological properties of magmas at sub-liquidus temperatures: Journal of Volcanology and Geothermal Research, v. 53, p. 47-66.

Press, W.H., Vetterling, W.T., Teukolsky, S.A., and Flannery, B.P., 1992, Numerical Recipes: Cambridge, Cambridge University Press, 933 p.

Proussevitch, A.A., and Sahagian, D.L., 1996, Dynamics of coupled diffusive and decompressive bubble growth in magmatic systems: Journal of Geophysical Research, B, Solid Earth and Planets, v. 101, p. 17,447-17,455.

Robie, R.A., Hemingway, B.S., and Fisher, J.R., 1978, Thermodynamic properties of minerals and related substances at $298.15 \mathrm{~K}$ and 1 bar $\left(10^{5}\right.$ Pascals $)$ pressure and at higher temperature: U.S. Geological Survey Bulletin 1452, 456 pp.

Roscoe, R., 1952, The viscosity of suspensions of rigid spheres: British Journal of Applied Physics, v. 3, p. 267-269.

Saad, M.A., 1985, Compressible Fluid Flow: Englewood Cliffs, NJ, Prentice-Hall, Inc., $560 \mathrm{p}$.

Schlichting, H., 1955, Boundary Layer Theory: New York, McGraw-Hill.

Shaw, H.R., 1965, Comments on viscosity, crystal settling, and convection in granitic magmas: American Journal of Science, v. 263, p. 120-152.

$\longrightarrow, 1969$, Rheology of basalt in the melting range: Journal of Petrology, v. 10, p. 510-535.

— 1972, Viscosities of magmatic silicate liquids: An empirical method of prediction: American Journal of Science, v. 272, p. 870-893.

Sibree, J.O., 1933, The viscosity of froth. Transactions of the Faraday Society, v. 2, pp. 325-331.

Sparks, R.S.J., 1978, The dynamics of bubble formation and growth in magmas: A review and analysis: Journal of Volcanology and Geothermal Research, v. 3, p. 1-37.

Stein, D.J., and Spera, F.J., 1992, Rheology and microstructure of magmatic emulsions: theory and experiments: Journal of Volcanology and Geothermal Research, v. 49, p. 157-174.

Taylor, G.I., 1932, The viscosity of a fluid containing small droplets of another fluid: Proceedings of the Royal Society of London, Series A, v. 146, p. 501-523.

Thomas, N., Jaupart, C., and Vergniolle, S., 1994, On the vesicularity of pumice: Journal of Geophysical Research, v. 99, p. 15633-15644.

Turcotte, D.L., Ockendon, H., Ockendon, J.R., and Cowley, S.J., 1990, A mathematical model for vulcanian eruptions: Geophysical Journal International, v. 103, p. 211-217. 
Vergniolle, S., and Jaupart, C., 1986, Separated two-phase flow and basaltic eruptions: Journal of Geophysical Research, v. 91, no. B12, p. 12842-12860.

Walker, G.P.L., Wilson, L., and Bowell, E.L.G., 1971, Explosive volcanic eruptions--I. The rate of fall of pyroclasts: Geophysical Journal of the Royal Astronomical Society, v. 22, p. 377-383.

Webb, S.L., and Dingwell, D.B., 1990, Non-Newtonian rheology of igneous melts at high stresses and strain rates: Experimental results for rhyolite, andesite, basalt, and nephelinite: Journal of Geophysical Research, v. 95, p. 15695-15701.

Wilson, L., and Head, J.W.I., 1981, Ascent and eruption of basaltic magma on the earth and moon: Journal of Geophysical Research, v. 86, no. B4, p. 2971-3001.

Wilson, L., Sparks, R.S.J., and Walker, G.P.L., 1980, Explosive volcanic eruptions--IV. The control of magma properties and conduit geometry on eruption column behaviour: Geophysical Journal of the Royal Astronomical Society, v. 63, p. 117-148.

Woods, A., 1995, The dynamics of explosive volcanic eruptions: Reviews of Geophysics, v. 33, p. 495-530.

Woods, A.W., and Koyaguchi, T., 1995, Transitions between explosive and effusive eruptions of silicic magmas: Nature, v. 370, p. 641-644. 


\section{Appendix A: Calculating M elt Thermodynamics}

Following the methodology of Ghiorso and Sack (1995), a naturally occurring melt of a given composition can be considered to be a combination of certain end-member components, listed in Table A1. For each non-aqueous component, $\bar{c}_{p}$ (the specific heat in $\mathrm{J} / \mathrm{mole}$ ) of the melt has been determined experimentally and is assumed to be independent of temperature (detailed studies of individual melts (Neuville et al., 1993) show a weak temperature dependence). From experimental data, Ghiorso and Sack also give the molar volume of each component, $\bar{v}$, and its derivatives, $(\partial \bar{v} / \partial T),(\partial \bar{v} / \partial p)$, $\left(\partial^{2} \bar{v} / \partial T \partial p\right)$, and $\left(\partial^{2} \bar{v} / \partial p^{2}\right)$ at conditions of $T=1673 \mathrm{~K}, p=1 \mathrm{~atm}$.

Specific heat, density, and coefficient of thermal expansion of the melt

Ghiorso and Sack (1995) use a regular solution model, which assumes that the molar heat $\left(\bar{c}_{p m}\right)$, volume $\left(\bar{v}_{m}\right)$, and partial of volume with temperature of the melt are weighted sums of the properties for component $i$ :

$$
\begin{gathered}
\bar{c}_{p m}=\sum_{i=1}^{n} x_{i} \bar{c}_{p i}^{l i q} \\
\bar{v}_{m}=\sum_{i=1}^{n} x_{i} \bar{v}_{i}^{o} \\
\frac{\partial \bar{v}_{m}}{\partial T}=\sum_{i=1}^{n} x_{i}\left(\frac{\partial \bar{v}_{i}^{o}}{\partial T}\right) \\
\frac{\partial \bar{v}_{m}}{\partial p}=\sum_{i=1}^{n} x_{i}\left(\frac{\partial \bar{v}_{i}^{o}}{\partial p}\right)
\end{gathered}
$$

where $x_{i}$ is the mole fraction of each component. The overlines indicate that these terms are given per mole rather than per kilogram of melt.

Table A1: Names and formulas of end-member components in melt

\section{Formula of end- member component}

$$
\begin{gathered}
\mathrm{SiO}_{2} \\
\mathrm{TiO}_{2} \\
\mathrm{Al}_{2} \mathrm{O}_{3} \\
\mathrm{Fe}_{2} \mathrm{O}_{3} \\
\mathrm{Fe}_{2} \mathrm{SiO}_{4} \\
\mathrm{Mg}_{2} \mathrm{SiO}_{4} \\
\mathrm{CaSiO}_{3} \\
\mathrm{Na}_{2} \mathrm{SiO}_{3} \\
\mathrm{KaISiO}_{4} \\
\mathrm{H}_{2} \mathrm{O}
\end{gathered}
$$

Component name

amorphous silica rutile corundum hematite fayalite forsterite pseudowollastonite sodium metasilicate kalsilite water 
Conflow converts these terms from per-mole values to per-kilogram values by multiplying each by the average molecular weight of the melt $\left(M_{t o t}\right)$, in $\mathrm{kg} / \mathrm{mole}$ :

$$
\begin{gathered}
M_{t o t}=\sum_{i=1}^{n} x_{i} \bar{M}_{i} \\
c_{p m}=\frac{\bar{c}_{p m}}{M_{t o t}} \\
\rho_{m}=\frac{M_{t o t}}{\bar{v}_{m}} \\
\text { coefficient of thermal expansion }=\frac{1}{\bar{v}_{m} M_{t o t}} \frac{\partial \bar{v}_{m}}{\partial T} \\
\text { bulk modulus, } K_{m}=\frac{M_{t o t}}{\rho_{m}\left(\partial \bar{v}_{m} / \partial p\right)}
\end{gathered}
$$

where $\bar{M}_{i}$ is the total mass of component $i$ per mole of melt.

Thermodynamic properties of the melt

Ghiorso and Sack (1995), use a regular solution model to calculate the main thermodynamic properties of silicate melts. Their formula for the molar Gibbs free energy of the melt follows:

$$
\begin{gathered}
\bar{g}=\sum_{i=1}^{n} x_{i} \bar{g}_{i}^{o}+R T \sum_{i=1}^{n} x_{i} \ln x_{i}+\frac{1}{2} \sum_{i=1}^{n} \sum_{j=1}^{n} w_{i j} x_{i} x_{j}+ \\
R T\left[x_{w} \ln x_{w}+\left(1-x_{w}\right) \ln \left(1-x_{w}\right)\right]
\end{gathered}
$$

The subscripts $i$ and $j$ represent individual end-member components. The variable $w_{i, j}$ represents an interaction coefficient between components $i$ and $j$ in the melt. Ghiorso and Sack (1995) have estimated the values of these interaction coefficients, and we use their values in my calculations.

Using the identity $\bar{s}=-(\partial \bar{g} / \partial T)_{p}$ (Moran and Shapiro, 1994, p. 480), the previous equation can be differentiated to obtain the molar entropy:

$$
\bar{s}=\sum_{i=1}^{n} x_{i} \bar{s}_{i}^{o}-R \sum_{i=1}^{n} x_{i} \ln x_{i}-R\left[x_{w} \ln x_{w}+\left(1-x_{w}\right) \ln \left(1-x_{w}\right)\right]
$$


And, using the identity $\bar{h}=\bar{g}+T \bar{s}$, we can calculate $\bar{h}$ :

$$
\bar{h}=\sum_{i=1}^{n} x_{i} \bar{h}_{i}^{o}+\frac{1}{2} \sum_{i=1}^{n} \sum_{j=1}^{n} w_{i j} x_{i} x_{j}
$$

These formulas require numerical values of the molar enthalpy, entropy, and Gibbs free energy of each end-member component, expressions for which are given below.

M olar enthalpy of each component

If the enthalpy of each component at the reference temperature $\left(T_{r}=298 \mathrm{~K}\right)$ and pressure $\left(p_{r}=1 \mathrm{~atm}\right)$ are known, the enthalpy at other values of $T$ and $p$ can be calculated from the following formula:

$$
\begin{aligned}
\bar{h}_{T, p}^{o}= & \bar{h}_{T_{r}, p_{r}}^{o}+\int_{T_{r}}^{T_{\text {fusion }}}\left(\frac{\partial \bar{h}^{o}}{\partial T}\right)_{p_{r}} d T+T_{\text {fusion }} \Delta \bar{s}_{\text {fusion }, p_{r}}^{o} \\
& +\int_{T_{\text {fusion }}}^{T}\left(\frac{\partial \bar{h}^{o}}{\partial T}\right)_{p_{r}} d T+\int_{p_{r}}^{p}\left(\frac{\partial \bar{h}^{o}}{\partial p}\right)_{T} d p
\end{aligned}
$$

Substituting $(\partial \bar{h} / \partial T)_{p}=\bar{c}_{p}$ and $(\partial \bar{h} / \partial p)_{T}=\bar{v}-(\partial \bar{h} / \partial T)_{p}$ (Moran and Shapiro, 1994, p. 491), we get:

$$
\begin{aligned}
\bar{h}_{\text {app }, T, p}^{o}= & \bar{h}^{o}{ }_{T_{r}, p_{r}}+\int_{T_{r}}^{T_{\text {fusion }}} \bar{c}_{p}^{\text {sol }} d T+T_{\text {fusion }} \Delta \bar{s}_{\text {fusion }, p_{r}}^{o}+ \\
& \int_{T_{\text {fusion }}}^{T_{f}} \bar{c}_{p}^{l i q} d T+\int_{p_{r}}^{p_{f}}\left[\bar{v}-\left(\frac{\partial \bar{v}}{\partial T}\right)_{p}\right] d p
\end{aligned}
$$

where $\bar{c}_{p}^{s o l}$ and $\bar{c}_{p}^{\text {liq }}$ are specific heats of the solid and liquid phases, respectively; $\Delta \bar{s}_{\text {fusion, } p_{r}}^{o}$ is the molar entropy of melting at 1 atm pressure, and $T_{\text {fusion }}$ is the melting temperature at $p_{r}$. The first term on the right represents the enthalpy of formation the component from the elements at $p=1 \mathrm{~atm}, T=298 \mathrm{~K}$. The second term represents the increase in enthalpy as the mineral is heated to its melting point at $1 \mathrm{~atm}$ pressure. The third represents the enthalpy of fusion of the component at 1 atm pressure, and the fourth represents the enthalpy added to the melt by heating from the melting point to the final temperature.

The terms to the right of the final integral in Eq. (A14) represent the enthalpy change associated with increasing the pressure of the melt, at the final temperature, from 1 atm to the given pressure. It is calculated by dividing it into its two components: (1) the 
integral of $\bar{v} d p$, and (2) the integral of $-(\partial \bar{v} / \partial T)_{T_{f}} d p$. The term $\bar{v} d p$ is integrated as follows (Ghiorso and Sack, 1995):

$$
\begin{gathered}
\int_{p_{r}}^{p_{f}} \bar{v} d p=\left[\bar{v}_{1673 K, p_{r}}+\left(\frac{\partial \bar{v}}{\partial T}\right)_{p_{r}}\left(T_{f}-1673\right)\right]\left(p_{f}-p_{r}\right)+ \\
{\left[\left(\frac{\partial \bar{v}^{o}}{\partial p}\right)_{T}+\left(\frac{\partial^{2} \bar{v}^{o}}{\partial T \partial p}\right)(T-1673)\right]\left(\frac{p_{f}^{2}}{2}-p_{r} p_{f}+\frac{p_{r}^{2}}{2}\right)+} \\
\left.\left(\frac{\partial^{2} \bar{v}^{o}}{\partial p^{2}}\right) \frac{p_{f}^{3}}{6}-\frac{p_{r} p_{f}^{2}}{2}+\frac{p_{r}^{2} p_{f}}{2}-\frac{p_{r}^{3}}{6}\right)
\end{gathered}
$$

where the molar volume of each component $\left(\bar{v}_{1673 K, p_{r}}^{o}\right)$ and each of its partial derivatives have been tabulated (Ghiorso and Sack, 1995). The derivatives of molar volume are determined experimentally and are approximated as independent of temperature and pressure. This approximation makes it possible to solve the second term as

$$
-\int_{p_{r}}^{p_{f}}(\partial \bar{v} / \partial p)_{T} d p=-(\partial \bar{v} / \partial p)_{T}\left(p_{f}-p_{r}\right)
$$

Because the melt is in a liquid state, each component is assumed to be a liquid regardless of whether the melt temperature lies is above or below the fusion temperature for that particular component. The resulting enthalpy of each component is termed an apparent enthalpy by Ghiorso and Sack (1995), reflecting the fact that such end-member components may not necessarily exist as separate melts at the temperature and pressure specified.

M olar entropy of each component

Like molar enthalpy, the molar entropy can be calculated by integrating from the standard state of $T=298 \mathrm{~K}, p=1 \mathrm{~atm}$ :

$$
\bar{s}_{a p p, T_{f}, p_{f}}^{o}=\bar{s}_{T_{r}, p_{r}}^{o}+\int_{T_{r}}^{T_{f}}\left(\frac{\partial \bar{s}^{o}}{\partial T}\right)_{p_{r}} d T+\int_{p_{r}}^{p_{f}}\left(\frac{\partial \bar{s}^{o}}{\partial p}\right)_{T} d p
$$

where $\bar{s}_{T_{r}, p_{r}}^{o}$ is the absolute entropy of the component at the reference temperature and pressure. Substituting $\left(\partial \bar{s}^{o} / \partial T\right)_{p}=\bar{c}_{p} / T$ and $(\partial \bar{s} / \partial p)_{T}=-(\partial \bar{v} / \partial T)_{p}$ (Moran and Shapiro, 1994, p. 491), we get:

$$
\bar{s}_{\text {app }, T_{f}, p_{f}}^{o}=\bar{s}_{T_{r}, p_{r}}^{o}+\int_{T_{r}}^{T_{\text {fusion }}} \frac{\bar{c}_{p}^{\text {sol }}}{T} d T+\Delta \bar{s}_{\text {fusion }, p_{r}}^{o}+\int_{T_{\text {fusion }}}^{T} \frac{\bar{c}_{p}^{\text {liq }}}{T} d T-\int_{p_{r}}^{p_{f}}\left(\frac{\partial \bar{v}^{o}}{\partial T}\right)_{p} d p
$$


The values of $\bar{s}_{T_{r}, p_{r}}^{o}, \bar{c}_{p}^{\text {sol }}$ and $\bar{c}_{p}^{\text {liq }}$ are obtained by experiment (Berman, 1988; Ghiorso and Sack, 1995). The value of $\left(\partial \bar{v}^{o} / \partial T\right)_{p}$ is also obtained by experiment (Ghiorso and Sack, 1995), and is approximated as being independent of temperature.

Molar Gibbs free energy of each component

The molar Gibbs free energy $\left(\bar{g}_{T, p}^{o}\right)$ is calculated from the molar enthalpy and temperature using the definition of $\bar{g}$ :

$$
\bar{g}_{T, p}^{o}=\bar{h}_{T, p}^{o}-T \bar{s}_{T, p}^{o}
$$

Values of $\bar{g}_{w}^{o}$ were calculated at the given temperature and pressure using the following formula, from Nicholls (1980):

$$
\bar{g}_{w}^{o}=R T\left(\frac{A}{T}+B+\Phi_{p}\right)
$$

where $A$ and $B$ are constants whose values were determined from experimental data by Nicholls. The value $\Phi_{p}$ is the integral of specific volume with pressure:

$$
\begin{aligned}
& \Phi_{p}=\frac{1}{R T} \int_{p=0}^{p_{f}} v d p=\left[\frac{0.110}{T}+4.432 e-5+1.405 e-7\right] p \\
& +\left[\frac{7.337 e-8}{T}-1.17 e-8-9.502 \cdot 10^{-13} T\right] p^{2} \\
& +\left[\frac{1.876 e-10}{T}+4.586 \cdot 10^{-13}\right] p^{3}-\frac{1.191 \cdot 10^{-14}}{T} p^{4}
\end{aligned}
$$

where (Following Burnham and Davis, 1974) $p$ is in bars, and $T$ is in Kelvin. The above equation uses partial molar volumes of water in melt that were determined experimentally by Burnham and Davis $(1971,1974)$ for albite. For $T=973-1473 \mathrm{~K}\left(700^{\circ}-1200^{\circ} \mathrm{C}\right)$ and $\mathrm{p}=1-1000$ bars, results from Burnham and Davis give $\bar{v}_{w m}^{o}=20-35 \mathrm{~cm}^{3} / \mathrm{mole}$ - somewhat more than the $18 \mathrm{~cm}^{3} /$ mole for liquid water at $25^{\circ} \mathrm{C}$. More recent studies (Ochs and Lange, 1999) give somewhat smaller values of $\bar{v}_{w}\left(\sim 15-25 \mathrm{~cm}^{3} / \mathrm{mole}\right)$.

The MELTS program of Ghiorso and Sack (1995) uses values of $A$ (-33676.0 $\mathrm{J} /($ mole $\mathrm{K})$ ) and $B(18.3527 \mathrm{~J} / \mathrm{mole})$ ) that are optimized for data on water solubility. The above equation indicates that the chemical potential of water in the melt is a linear function of absolute temperature; and because $\left(\partial \bar{\mu}_{w}^{*} / \partial \boldsymbol{T}\right)_{p}=\bar{s}_{w}^{*}$, this relationship implies that the molar entropy of dissolved water does not change with pressure at $p=0$. 
To calculate the chemical potential of water, we modify the equation of Nicholls, above, by subtracting out the Gibbs free energy of supercritical water tabulated by Robie et al. (1978) and adding the identical quantity from Haar et al. (1984). This insures the thermodynamic properties of the $\mathrm{H}_{2} \mathrm{O}$ component are internally consistent with those of the supercritical fluid.

The enthalpy and entropy of dissolved water are calculated from the following thermodynamic relations:

$$
\begin{aligned}
& \bar{s}_{w}^{o}=-\left(\frac{\partial \bar{g}_{w}^{o}}{\partial T}\right)_{p} \\
& \bar{h}_{w}^{o}=\bar{g}_{w}^{o}+T \bar{s}_{w}^{o}
\end{aligned}
$$

Partial M olar Properties

The partial molar enthalpy of each component $i$ can be estimated as follows:

$$
\bar{h}_{i}=\bar{h}_{i}^{o}+\sum_{j=1}^{n} w_{i j} x_{j}-\frac{1}{2} \sum_{j=1}^{n} \sum_{k=1}^{n} w_{j k} x_{j} x_{k}
$$

The partial molar entropy of each component except $\mathrm{H}_{2} \mathrm{O}$ is:

$$
\bar{s}_{i}=\bar{s}_{i}^{o}-R \ln x_{i}-R \ln \left(1-x_{w}\right)
$$

For $\mathrm{H}_{2} \mathrm{O}$, it is:

$$
\bar{s}_{w}=\bar{s}_{w}^{o}-2 R \ln x_{w}
$$

The partial molar Gibbs free energy of each component except $\mathrm{H}_{2} \mathrm{O}$ is:

$$
\bar{\mu}_{i}=\bar{\mu}_{i}^{o}+R \boldsymbol{T}\left[\ln x_{i}+\ln \left(1-x_{w}\right)\right]+\sum_{j=1}^{n} w_{i j} x_{j}-\frac{1}{2} \sum_{j=1}^{n} \sum_{k=1}^{n} w_{j k} x_{j} x_{k}
$$

For water dissolved in the melt, it is

$$
\bar{\mu}_{w}=\bar{\mu}_{w}^{o}+2 R \boldsymbol{T} \ln x_{w}+\sum_{j=1}^{n} w_{w j} x_{j}-\frac{1}{2} \sum_{j=1}^{n} \sum_{k=1}^{n} w_{j k} x_{j} x_{k}
$$

Equation (A28) is used to calculate gas solubility in the melt. When the melt is saturated with gas, this term should equal the Gibbs Free Energy of pure $\mathrm{H}_{2} \mathrm{O}$ gas at the same pressure and temperature. 


\section{Appendix B: Calculating the Capillary Number}

The capillary number in a cylindrical conduit can be calculated as long as the strain rate, the average bubble radius, the melt viscosity, and the melt surface tension can be evaluated. The melt surface tension is taken to be $0.34 \mathrm{~N} / \mathrm{m}$ (Proussevitch and Sahagian, 1996). Melt viscosity is calculated as described in the body of this report. Other values are calculated as follows:

Shear strain rate. For laminar flow in a cylindrical conduit, the velocity profile is parabolic and follows the relation:

$$
u^{r}=u_{\max }\left(1-\frac{\boldsymbol{r}^{2}}{\boldsymbol{R}^{2}}\right)
$$

where $u^{r}$ is the velocity at a given distance $\boldsymbol{r}$ from the conduit center, and $\boldsymbol{R}$ is the conduit radius. The average velocity in the conduit, $u$, is equal to $u_{\max } / 2$ (Bird et al., 1960, p. 46). The shear-strain rate at a given distance $\boldsymbol{r}$ from the conduit center is equal to $d u_{r} / d \boldsymbol{r}$ :

$$
\dot{\varepsilon}_{r z}^{r}=-\frac{u_{\max } \boldsymbol{r}}{\boldsymbol{R}^{2}}=-\frac{u \boldsymbol{r}}{2 \boldsymbol{R}^{2}}
$$

The average shear strain rate, $\dot{\varepsilon}_{r z}$, is equal to the shear rate $\dot{\varepsilon}_{r z}^{r}$, integrated from $r=0$ to $\boldsymbol{r}=\boldsymbol{R}$ over cylindrical shells of infinitesimal cross-sectional area $2 \pi \boldsymbol{r} d \boldsymbol{r}$, divided by the cross sectional area of the conduit:

$$
\dot{\varepsilon}_{r z}=\frac{1}{\pi \boldsymbol{R}^{2}} \int_{r=0}^{r=\boldsymbol{R}}-\frac{u \boldsymbol{r}}{2 \boldsymbol{R}^{2}} 2 \pi \boldsymbol{r} d \boldsymbol{r}=-\frac{u}{3 \boldsymbol{R}}
$$

Integrating this equation, the absolute value of the average shear strain is $\dot{\varepsilon}=2 u / 3 \boldsymbol{R}$

Average bubble radius. The average bubble radius $(r)$ is calculated from the volume of gas per unit volume of melt $\left(v_{g} / v_{m}\right)$, divided by the number of bubbles per cubic meter of melt ( $N$, the "bubble-number density"). The quotient $\left(V_{g} /\left(N v_{m}\right)\right)$, which is the average volume per bubble, is converted to $r$ using the formula for the volume of a spherical bubble. For basaltic lava-fountain tephra, Mangan and Cashman (1996) have measured bubble-number densities of about $10^{10}$ bubbles per cubic meter of melt. Cashman et al. (2000) report number densities of $10^{14}-10^{16} / \mathrm{m}^{3}$ for tephra clasts from silicic plinian eruptions. Therefore we calculate an approximate bubble-number density as follows:

$$
\log (N) \approx 20 \cdot \hat{m}_{\mathrm{SiO}_{2}}
$$

where $\hat{m}_{\mathrm{SiO}_{2}}$ is the mass fraction $\mathrm{SiO}_{2}$ in the melt. 


\section{Appendix C: Modifying the Source Code to use Papale's Fragmentation Criterion}

To use Papale's fragmentation model, you will need to obtain the Fortran source code to Conflow, which can be obtained from a subdirectory of the ftp site "Elektra.wr.usgs.gov/Ftp_Access/Pub/Conflow. Edit the source code as follows:

1) In the main program, named "main.f", on or around line 111 , remove the "c" from the beginning of the following line of code:

c read $\left(8,{ }^{*}\right)$ ifragtype

2) In the same file, on or around line 140, add a "c" to the first column of the following line of code:

$$
\text { ifragtype }=2 \quad \text { ! sets fragmentation type to vfgas }=0.75
$$

The lines of code that determine whether the melt has fragmented are on or around lines 703-710, and look like:

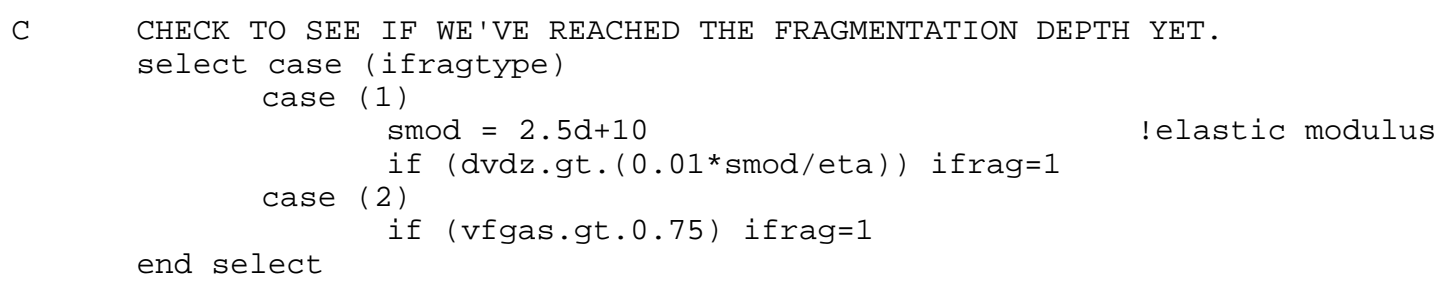

The variable smod refers to the elastic modulus, et a refers to the bulk viscosity, and dvdz is the extensional strain rate in the conduit. You may wish to judiciously consider their values and how they are calculated.

3) To the input file conin, Add the following line immediately below the line that gives the input value for $\mathrm{wt} \% \mathrm{~K} 2 \mathrm{O}$ :

fragmentation criterion (=1 for Papale, 2 for vfgas=0.75)

To use Papale's fragmentation criterion, make sure that the integer at the beginning of this line equals 1 . To use the $v_{g}=0.75$ fragmentation criterion, change it to 2 .

4) Recompile the program. A readme.txt file in the ftp directory containing the source code will tell you how to do this. You will now have the option of choosing either Papale's fragmentation criterion (by entering a "1" at that line of the input file), or $v_{g}=0.75$. However, you will not be able to use this version with the Windows ${ }^{\circledR}$-based front end. You will have to run your models from the DOS window (if using a DOS or Windows ${ }^{\circledR}$-based machine) or from the command line (for other operating systems.

\section{Appendix D: Calculating $u_{\max }$}

If the erupting mixture reaches the conduit exit before the pressure has dropped to 1 atmosphere, it will abruptly expand to equilibrate with atmospheric pressure. Expansion 
and adiabatic cooling will accompany this decompression. If these processes take place without frictional dissipation of energy, the process is said to be isentropic, and maximum amounts of acceleration and cooling can be calculated. In this program the calculations are done with the assumption that the mixture acts as an ideal "pseudogas" (Kieffer, 1984). That is, the mixture's bulk properties approximately follow the ideal gas relationship, $p v=n R T$. For ideal gases and pseudogases expanding under adiabatic, isentropic conditions, the pressure and temperature before and after decompression are related by the equation (Moran and Shapiro, 1992, p. 104):

$$
\frac{T_{e}}{T_{f}}=\left(\frac{p_{e}}{p_{f}}\right)^{(\gamma-1) / \gamma}
$$

where the subscript $f$ refers to the "final" value in the conduit, before decompression, and "e" refers to the value after decompression. Temperatures are absolute. The variable $\gamma$ is the ratio $c_{p} / c_{v}$, where $c_{p}$ and $c_{v}$ are the specific heats at constant pressure and constant volume, respectively, of the magma-gas mixture. Those specific heats are given by the equations:

$$
\begin{gathered}
c_{p}=m_{g} c_{p, g}+m_{m} c_{p, m}+m_{x} c_{p, x} \\
c_{v}=m_{g} c_{v, g}+m_{m} c_{v, m}+m_{x} c_{v, x}
\end{gathered}
$$

where $c_{p, g}, c_{v, g}$, are the specific heats at constant pressure and volume, respectively, of the gas phase, $c_{p, m}$ and $c_{v, m}$ are the specific heats at constant $p$ and $T$, respectively, of the liquid magma, and $c_{p, x}$ and $c_{v, x}$ are the analogous values for the crystal phase. we assume that $c_{p, m}=c_{v, m}$ and $c_{p, x}=c_{v, x}$. Specific heats of the gas phase are calculated using the method of Haar et al. (1984). The specific heat of the liquid magma is calculated using the methodology of Ghiorso and Sack (1995; Appendix A).

Once the adiabatic temperature change has been calculated, the change in specific enthalpy $(h)$ of the mixture during decompression is computed from the following equation for ideal gases (Moran and Shapiro, 1992, p. 96):

$$
h_{e}-h_{f}=c_{p}\left(T_{\mathrm{e}}-T_{\mathrm{f}}\right)
$$

In addition to assuming ideal gas behavior, this equation assumes that $c_{p}$ is invariant over the range of temperatures experienced during decompression.

The maximum theoretical velocity is then calculated assuming that all of the change in enthalpy of the expanding mixture is transformed into kinetic energy. This implies that an insignificant amount of energy goes into lifting of the material or to frictional heating. Given these assumptions, the maximum theoretical velocity $\left(u_{\max }\right)$ is:

$$
u_{\text {max }}=\sqrt{u_{f}^{2}+2\left(h_{f}-h_{e}\right)}
$$

